\title{
Electronic structure determination using an assembly of conventional and synchrotron techniques: The case of a xanthate complex
}

\author{
Luciana C. Juncal a , José Avila ${ }^{\mathrm{b}}$, Maria Carmen Asensio ${ }^{\mathrm{b}}$, Carlos O. Della Védova ${ }^{\mathrm{a}}$, Rosana M. Romano ${ }^{\mathrm{a}, *}$

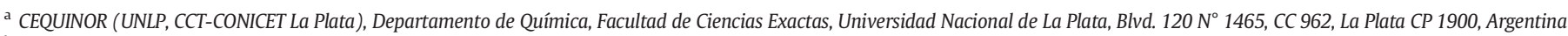 \\ b Synchrotron SOLEIL, Orme des Merisiers - Saint Aubin BP 48, 91192 Gif sur Yvette Cedex, France
}

\section{A R T I C L E I N F O}

Article history:

Received 10 June 2016

Received in revised form 26 February 2017

Accepted 1 March 2017

Available online 3 March 2017

\section{Keywords:}

X-ray absorption spectroscopy

Resonance Raman spectroscopy

Photoelectron spectroscopy

UV-visible spectroscopy

\begin{abstract}
A B S T R A C T
The electronic properties of the coordination complex nickel (II) bis-n-propylxanthate, $\mathrm{Ni}\left(\mathrm{CH}_{3}\left(\mathrm{CH}_{2}\right)_{2} \mathrm{OC}(\mathrm{S}) \mathrm{S}\right)_{2}$, were studied by a combination of complementary experimental (both laboratory and synchrotron based techniques) and theoretical methods. Energy differences between HOMOs and LUMOs were determined from UV-visible spectroscopy. The assignment of the transitions were performed with the aid of TD-DFT calculations and based in symmetry considerations. The analysis of the Raman excitation profiles of selected vibrational modes of the complex, taken in resonance with a particular electronic transition, was found to reinforce the electronic assignment. Experimental binding energies of inner and core electrons were determined by PES measurements. Ni K-edge, S K-edge, Ni L-edge, O K-edge and C K-edge XANES spectra were interpreted in terms of the promotion of core electrons to unoccupied electronic levels. An experimental quantitative molecular orbital diagram was constructed using the information extracted from the different techniques.
\end{abstract}

(c) 2017 Elsevier B.V. All rights reserved.

\section{Introduction}

The knowledge of the electronic structure of coordination compounds is essential to understand their reactivity. Nowadays, several spectroscopic techniques, particularly synchrotron-based methods, are available to study the electronic structure of coordination complexes and related materials [1]. For example, photoelectron spectroscopy, PES, allows the determination of experimental binding energies of valence or core electrons. In X-ray absorption spectroscopy (XAS), particularly in X-ray Absorption Near Edge Structure (XANES) spectroscopy, core electrons are promoted to unoccupied electronic levels. XANES provides structural (local symmetry) and electronic information of the absorbing elements since it is very sensitive to the local bonding environment, such as the number of valence electrons, their spin configurations, the formal charge of the absorber and the symmetry and coordination number (chemical nature and geometrical arrangement of the ligands) [2-5].

Our research group has been interested during the last years in the preparation of xanthate $(-\mathrm{OC}(\mathrm{S}) \mathrm{S}-)$ compounds and coordination complexes with xanthate ligands (see for example references [6,7] and references cited therein), motivated in their wide variety of applications. Recently, coordination complexes with a general formula $\mathrm{Ni}(\mathrm{ROC}(\mathrm{S}) \mathrm{S})_{2}$ were used in the preparation of NiS nanoparticles and thin films, with applications in semiconductor materials, heterogeneous catalysis, and

\footnotetext{
* Corresponding author.

E-mail address: romano@quimica.unlp.edu.ar (R.M. Romano).
}

photogalvanic cells [8,9]. Another interesting property of the xanthate compounds is their ability as activators in froth flotation processes, used to improve the recovery $[10,11]$. Xanthate salts, xanthogen compounds, and their metal coordination complexes have been also receive special attention regarding their potential pharmacological uses. Studies of their antiviral, antibacterial, antitumoral, and antioxidant properties, between others, have been reported [12-17].

In this work, and as part of a general project aimed to the detailed electronic structure determination of different xanthate compounds, we present the study of nickel (II) bis-n-propylxanthate, $\mathrm{Ni}\left(\mathrm{CH}_{3}\left(\mathrm{CH}_{2}\right)_{2} \mathrm{OC}(\mathrm{S}) \mathrm{S}\right)_{2}$, through a combination of complementary experimental techniques and theoretical methods. The single-crystal structure of the complex was previously reported $[18,19]$, with the two bidentate ligands coordinating the $\mathrm{Ni}(\mathrm{II})$ ion in a square-planar geometry. The whole complex belongs to the $\mathrm{C}_{2}$ symmetry point group, while the central $-\mathrm{OCS}_{2} \mathrm{NiS}_{2} \mathrm{CO}$ - moiety presents a local symmetry that can be assumed as $\mathrm{D}_{2 \mathrm{~h}}$.

Four different types of experimental techniques were used in this work to study the electronic structure of the title complex, two of them using synchrotron-based methods (PES and XANES) and the other two with laboratory-based techniques (UV-visible and resonance Raman spectroscopy). In the first place of the Results and Discussion Section, results of the UV-visible spectroscopy are presented. The absorption bands of the spectra were interpreted, with the aid of TD-DFT calculations, in terms of transitions between valence occupied molecular orbitals (HOMOs) and low-energy unoccupied molecular orbitals (LUMOs). Secondly, Raman spectra in resonance with one of the 
electronic transition were analyzed. The identification of the enhanced vibrational modes in the Raman excitation profile was used as a useful criterion to reinforce the previous electronic assignment. Experimental binding energies of shallow and core electrons were determined by PES measurements performed in SOLEIL synchrotron facility. XANES spectra, presented at the end of the Results and Discussion Section, were taken during one campaign to SOLEIL (for C K-edge, O K-edge, and Ni L-edge electrons), and two campaigns to LNLS (for S K-edge and Ni K-edge electrons). These results were interpreted in terms of a promotion of core electrons to unoccupied electronic levels.

\section{Experimental Section}

\subsection{Materials}

Reagents $\left(\mathrm{CH}_{3}\left(\mathrm{CH}_{2}\right)_{2} \mathrm{OH}, \mathrm{CS}_{2}, \mathrm{KOH}\right.$ and $\left.\mathrm{NiCl}_{2} \cdot 6 \mathrm{H}_{2} \mathrm{O}\right)$ were purchased reagent grade and used without further purification. Solvents $\left(\mathrm{CH}_{3} \mathrm{CH}_{2} \mathrm{OCH}_{2} \mathrm{CH}_{3}, \mathrm{CH}_{3} \mathrm{C}(\mathrm{O}) \mathrm{CH}_{3}, \mathrm{CCl}_{4}, \mathrm{CHCl}_{3}, \mathrm{CH}_{3} \mathrm{OH}\right.$ and $\left.\mathrm{CH}_{3} \mathrm{CN}\right)$ were dried using molecular sieves and subsequently distilled. Potassium npropylxanthate, $\mathrm{CH}_{3}\left(\mathrm{CH}_{2}\right)_{2} \mathrm{OC}(\mathrm{S}) \mathrm{SK}$, was prepared and purified according to literature procedures from $\mathrm{KOH}, \mathrm{CS}_{2}$, and the corresponding alcohol, $\mathrm{CH}_{3}\left(\mathrm{CH}_{2}\right)_{2} \mathrm{OH}[20]$.

\subsection{Synthesis}

Nickel (II) bis-n-propylxanthate, $\mathrm{Ni}\left(\mathrm{CH}_{3}\left(\mathrm{CH}_{2}\right)_{2} \mathrm{OC}(\mathrm{S}) \mathrm{S}\right)_{2}$, was synthesized by treatment of $\mathrm{K}^{+}\left[\mathrm{CH}_{3}\left(\mathrm{CH}_{2}\right)_{2} \mathrm{OC}(\mathrm{S}) \mathrm{S}^{-}\right]$with $\mathrm{NiCl}_{2} \cdot 6 \mathrm{H}_{2} \mathrm{O}$ in acetone solution, as reported previously, according with the following equation $[18,21]$ :

$$
\begin{aligned}
& \mathrm{CH}_{3}\left(\mathrm{CH}_{2}\right)_{2} \mathrm{OH}+\mathrm{CS}_{2}+\mathrm{KOH} \rightarrow \mathrm{K}^{+}\left[\mathrm{CH}_{3}\left(\mathrm{CH}_{2}\right)_{2} \mathrm{OC}(\mathrm{S}) \mathrm{S}\right]^{-}+\mathrm{H}_{2} \mathrm{O} \\
& 2 \mathrm{CH}_{3}\left(\mathrm{CH}_{2}\right)_{2} \mathrm{OC}(\mathrm{S}) \mathrm{S}^{-}+\mathrm{Ni}^{2+} \rightarrow \mathrm{Ni}\left(\mathrm{CH}_{3}\left(\mathrm{CH}_{2}\right)_{2} \mathrm{OC}(\mathrm{S}) \mathrm{S}\right)_{2}
\end{aligned}
$$

The reaction mixture was kept under constant stirring at room temperature for $2 \mathrm{~h}$, after which the mixture was filtered and a dark green translucent solution was obtained. The solvent was allowed to slowly evaporate until olive green crystals were obtained. The final purity was assayed by FTIR and FTRaman.

\subsection{UV-Visible Spectroscopy}

The UV-visible spectra of $\mathrm{Ni}\left(\mathrm{CH}_{3}\left(\mathrm{CH}_{2}\right)_{2} \mathrm{OC}(\mathrm{S}) \mathrm{S}\right)_{2}$ were recorded in solution, using solvents with different polarities, in the region from 190 to $900 \mathrm{~nm}$ at room temperature either on a Hewlett Packard $8452 \mathrm{~A}$ or on a Shimazdu UV-2600 UV-VIS spectrophotometer. The experimental oscillator strength of a transition $\left(f_{\text {nm }}\right)$ was calculated with Eq. (1),

$f_{\mathrm{nm}}=\frac{4 \varepsilon_{0} m_{e} c^{2} \ln 10}{N_{A} \varepsilon^{2}} \int_{\text {band }} \varepsilon(\omega) d \omega \cong 4.319 \times 10^{-9}\left(\mathrm{Mcm}^{2}\right) \int_{\text {band }} \varepsilon(\omega) d \omega(1)$

where $\varepsilon$ is the molar absorptivity $\left(\mathrm{L} \cdot \mathrm{mol}^{-1} \cdot \mathrm{cm}^{-1}\right), \omega$ the wavenumber $\left(\mathrm{cm}^{-1}\right), \mathrm{m}_{e}$ the electron mass, $h$ the Planck's constant, $c$ the speed of light, $N_{A}$ the Avogadro's number and $\varepsilon_{0}$ the vacuum permittivity. The integrated intensity of a band, $\int_{\text {band }} \varepsilon(\omega) d \omega$, also called integrated molar extinction coefficient, is the area under the absorption band of a defined $\omega$ interval, represented as molar absorptivity, $\varepsilon(\omega)$, versus $\omega$ [22-25].

\subsection{FTIR Spectroscopy}

The FTIR spectrum was recorded on a Nexus Nicolet instrument equipped with either an MCTB or a DTGS detector (for the ranges $4000-400 \mathrm{~cm}^{-1}$ or $600-100 \mathrm{~cm}^{-1}$, respectively) at room temperature and with a resolution of $4 \mathrm{~cm}^{-1}$. A total of 32 scans for each measurement were accumulated. The solid compound was measured in $\mathrm{KBr}$ (range 4000-400 $\mathrm{cm}^{-1}$ ) and polyethylene (range 600-100 $\mathrm{cm}^{-1}$ ) pellets.

\subsection{Raman Spectroscopy}

The FTRaman spectrum was measured in a Bruker IFS 66 FT-Raman spectrometer, using a FRA 106 Raman accessory, with a resolution of $4 \mathrm{~cm}^{-1}$, in the region between 3500 and $100 \mathrm{~cm}^{-1}$. The sample, placed in a sealed $2 \mathrm{~mm}$ diameter glass capillary, was excited with a $1064 \mathrm{~nm}$ Nd-YAG laser. A Raman triple grating Horiba Jobin Yvon T64000 spectrometer system, with a confocal microscope, CCD detector and $\mathrm{Ar}^{+}$ and $\mathrm{Kr}^{+}$multiline Coherent lasers, was also used to record Raman spectra of the sample, using either a metal carrier or $5 \mathrm{~mm}$ diameter glass tubes. The wavenumbers were calibrated with the $459 \mathrm{~cm}^{-1}$ band of $\mathrm{CCl}_{4}$.

The resonance or pre-resonance Raman effect was investigated using the dispersive spectrometer, and eight different excitation lines from the argon laser, with wavelengths between 528.7 and $457.9 \mathrm{~nm}$ and a $647.1 \mathrm{~nm}$ line of the krypton laser. $\mathrm{CH}_{3} \mathrm{C}(\mathrm{O}) \mathrm{CH}_{3}$ was employed as internal standard for the resonance Raman study. Raman spectra of the pure compound and in acetone solutions were measured. The Raman excitation profiles were built from the relative intensities of selected bands of the compound with respect to different Raman bands of acetone (786, 529 and $\left.1069 \mathrm{~cm}^{-1}\right)$.

\subsection{Synchrotron Techniques}

Three campaigns were needed to perform the atomic measurements, one in France using the SOLEIL facilities and two in Brazil at the LNLS synchrotron.

The ANTARES beamline of the French National Synchrotron Facility, SOLEIL, designed for complete electronic structure determination using scanning-angle-resolved photoemission spectromicroscopy combined with a local structural characterization by means of Nanoscale Angle Resolved Photo Emission Spectroscopy (Nano-ARPES) measurements and $\mathrm{X}$-ray absorption spectroscopy (XAS), was used to measure the XANES spectra at the $\mathrm{K}(1 \mathrm{~s})$ edge of the carbon and oxygen atoms, and the nickel L ( 2 p) edge. This beamline has a Planar Grating Monochromator (PGM) without entrance slits, using plane gratings with varied line spacing (VLS) and variable groove depth (VGP), and two detectors, a high energy and angle resolution kinetic energy electron analyzer (Scienta R4000) and a low energy fluorescence detector. The Scienta R4000 was used for measurements of photoelectron spectroscopy. The spectral resolution of the beamline is $\mathrm{E} / \Delta \mathrm{E}>20,000(10-150 \mathrm{eV})$ and $\mathrm{E} / \Delta \mathrm{E}>10,000(150-1000 \mathrm{eV})[26,27]$.

The XANES spectra at the $\mathrm{K}(1 \mathrm{~s})$ edge of sulfur atoms were measured at the D04A-SXS (Soft X-Ray Spectroscopy) beamline of the Brazilian Synchrotron Light Laboratory, LNLS, in Campinas, São Paulo, Brazil, that operates at the soft X-ray region (from 900 to $5500 \mathrm{eV}$ ). During the experiments, a $\mathrm{Si}$ (111) monochromator was used and the pressure was maintained below $5 \times 10^{-8}$ mbar. The resolution was $\Delta \mathrm{E}=0.45 \mathrm{eV}$ at $900 \mathrm{eV}(\mathrm{E} / \Delta \mathrm{E}=2000)$ and $\Delta \mathrm{E}=0.9 \mathrm{eV}$ at $5500 \mathrm{eV}(\mathrm{E} / \Delta \mathrm{E}=6000)$. The experimental chamber consists of a single camera for multiple samples, operating under a pressure of $10^{-7} \mathrm{mbar}$, and with three detection modes available: Total electron yield (TEY), Fluorescence yield (FY) and Transmission. A Keitlhey electrometer, model 6514 and 617, was used as the detection system for the TEY measurements [28-30].

The DO4B-XAFS1 beamline of the LNLS, that deliver photons in the hard X ray energy range between 4000 and $24,000 \mathrm{eV}$, was used to measure the $\mathrm{K}(1 \mathrm{~s})$ edge of the nickel atom. The beamline is composed by a Si (111) monochromator with a resolution of $\Delta \mathrm{E} / \mathrm{E}=1.31 \times 10^{-4}$ and an X-ray eye detector [31].

\subsubsection{Photoelectron Spectroscopy (PES)}

The photoelectron spectra were measured at the ANTARES beamline of the SOLEIL facility using different excitation energies in the range 
between 1000 and $100 \mathrm{eV}$. The kinetic energies $\left(\mathrm{E}_{\mathrm{C}}\right)$ of electrons ionized from core and inner shells of carbon, oxygen, sulfur and nickel atoms, as well as from valence molecular orbitals, were measured at $6{ }^{\circ} \mathrm{C}$, to reduce the surface charge effect occurring at higher temperatures. The value of the work function $(\varphi)$ was estimated for each spectrum from cutting the tangents to the baseline and to the peak corresponding to the kinetic energy closest to the excitation energy [32,33]. The binding energy $\left(E_{B}\right)$ of each electron was then calculated using Eq. (2):

$\mathrm{E}_{\mathrm{B}}=h \mathrm{v}-\mathrm{E}_{\mathrm{C}}-\phi$

where $h v$ corresponds to the excitation energy.

\subsubsection{X-ray Absorption Near Edge Structure (XANES) Spectroscopy}

The XANES spectra were recorded on TEY mode in different energy regions. To ensure reproducibility and increase the signal to noise ratio, 5 to 10 spectra taken in identical conditions were averaged. The background was corrected in all spectra by adjusting a polynomial in the region prior to the ionization potential and subtracting this polynomial to the entire spectrum. The normalization of the data was carried out by fitting a straight line or plane polynomial in the post-threshold region and normalizing the jump to 1.0 using the ATHENA program included in the FDMNES software [34,35]. Once measured and normalized each XANES spectra, the first and second derivatives were analyzed in order to properly locate the position of each of the resonance present in the spectra [36].

XANES spectra in the energy regions of excitation of the $1 \mathrm{~s}$ electrons (K-edge) of carbon and oxygen atoms and also of nickel 2p electrons ( Ledge) were carried out at $-157^{\circ} \mathrm{C}$. Solid samples were placed with a double-sided carbon tape on a metal holder. Each measurement was performed in the range of $270-310 \mathrm{eV}$ for C 1 s electrons, $520-600 \mathrm{eV}$ for $\mathrm{O} 1 \mathrm{~s}$ electrons and $840-900 \mathrm{eV}$ for Ni $2 \mathrm{p}$ electrons with an energy step between 0.08 and $0.20 \mathrm{eV}$. The XANES spectra in the region of excitation of the $1 \mathrm{~s}$ electrons (K-edge) of sulfur were recorded at room temperature. Solid samples were ground to a fine powder with an agate mortar and pestle, and placed on a double-sided sulfur free carbon tape. Energy was calibrated with the $2520 \mathrm{eV}$ value of the excitation energy of the Mo $1 \mathrm{~s}$ electrons (K-edge). Each spectrum was measured in the $2430-2530 \mathrm{eV}$ energy range, with a step of $0.08 \mathrm{eV}$. XANES spectra of the $1 \mathrm{~s}$ electrons $(\mathrm{K})$ of nickel atoms were taken at room temperature. Tablets of uniform shape and of $1 \mathrm{~mm}$ thickness, obtained from solid samples diluted in boron nitride, were placed in a sample holder. Energy was calibrated with the $8332.8 \mathrm{eV}$ value of the excitation energy of a nickel foil, measured simultaneously with the sample.

\subsection{Theoretical Calculations}

All quantum chemical calculations were performed with the Gaussian 03 program system [37], using the B3LYP method in combination with a $6-31+G^{*}$ basis set. Geometry optimization was sought using standard gradient techniques by simultaneous relaxation of all geometrical parameters, starting from the experimental structure determined by crystal X ray diffraction analysis $[18,19]$. The calculated vibrational properties correspond to a potential energy minimum for which no imaginary frequency was found. The obtained vibrational frequencies were scaled as follows: $0.94367^{*} v+24.84003$ [38], giving a very good correlation with experimental results. The electronic spectrum for the previously optimized structure was simulated using the TD-DFT formalisms, with a maximum of 100 states and $S=1[39,40]$.

The calculated electronic spectrum was visualized using the GaussSum 2.2 program [41]. The results from theoretical calculations, especially the animation of the vibrational displacement vectors and the representation of molecular orbitals were pictured using the graphical interface GaussView for Gaussian programs [42].

\section{Results and Discussion}

\subsection{Electronic Absorption Spectroscopy}

The UV-visible spectra of the nickel complex was measured in solutions of several concentrations in solvents with different polarities (chloroform, acetone and acetonitrile), as shown in Fig. 1. A list of absorption maxima of the spectra taken in $\mathrm{CH}_{3} \mathrm{CN}$ solutions is presented in Table 1, while Table S1 of the Supplementary Information contains the comparison of the UV-visible absorption maxima in solutions of different solvents. The molar absorptivities $(\varepsilon)$ for each peak (calculated from the absorbance vs. concentration plots in all cases with the exception of the one corresponding to the low-intensity $636 \mathrm{~nm}$ absorption that was estimated from the spectrum of the most concentrated solution only) and the experimental oscillator strength (calculated with Eq. (1) of the Experimental Section), are also included in the table.
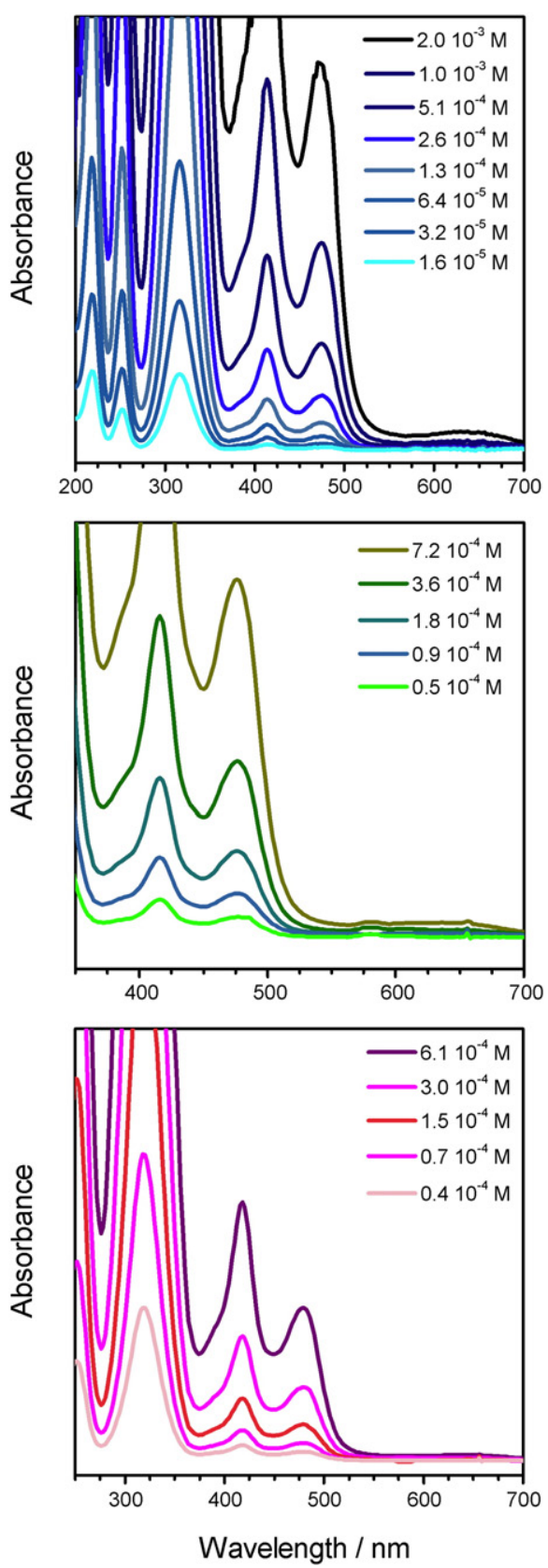

Fig. 1. UV-visible spectra of $\mathrm{Ni}\left(\mathrm{CH}_{3} \mathrm{CH}_{2} \mathrm{CH}_{2} \mathrm{OC}(\mathrm{S}) \mathrm{S}\right)_{2}$ in solution of $\mathrm{CH}_{3} \mathrm{CN}$ (top), $\mathrm{CH}_{3} \mathrm{C}(\mathrm{O}) \mathrm{CH}_{3}$ (middle) and $\mathrm{HCCl}_{3}$ (bottom). 
Table 1

Wavelenght $(\lambda, \mathrm{nm})$, molar absorptivities $\left(\varepsilon, \mathrm{L} \cdot \mathrm{mol}^{-1} \cdot \mathrm{cm}^{-1}\right)$ and experimental oscillator strength $\left(f_{\mathrm{nm}}\right)$ of the absorption maxima of the $\mathrm{UV}-\mathrm{Visible}$ spectra of $\mathrm{Ni}\left(\mathrm{CH}_{3}\left(\mathrm{CH}_{2}\right)_{2} \mathrm{OC}(\mathrm{S}) \mathrm{S}\right)_{2}$ in $\mathrm{CH}_{3} \mathrm{CN}$ solution, TD-B3LYP/6-31 $+\mathrm{G}^{*}$ calculated electronic transitions $(\lambda, \mathrm{nm})$, theoretical oscillator strength $(f)$ and tentative assignment of the bands.

\begin{tabular}{|c|c|c|c|c|c|}
\hline \multicolumn{2}{|c|}{ Experimental (in $\mathrm{CH}_{3} \mathrm{CN}$ solution) } & \multicolumn{2}{|c|}{ TD-B3LYP/6-31 + G* } & \multicolumn{2}{|l|}{ Assignment } \\
\hline $\begin{array}{l}\lambda / \mathrm{nm} \\
{\left[\varepsilon / \mathrm{L} \cdot \mathrm{mol}^{-1} \cdot \mathrm{cm}^{-1}\right]}\end{array}$ & $f_{n m}^{\mathrm{a}}$ & $\lambda^{\mathrm{b}} / \mathrm{nm}$ & $f$ & Electronic transition $^{c}$ & Approximate description \\
\hline $\begin{array}{l}218 \\
{[34000]}\end{array}$ & 0.73 & 216 & 0.19 & $\begin{array}{l}\text { HOMO- } 10 \rightarrow \text { LUMO + } 1 \\
B_{3 g} \rightarrow B_{1 u}\end{array}$ & $\pi \mathrm{S}-\mathrm{Ni} \rightarrow \pi^{*} \mathrm{OCS}_{2}$ \\
\hline $\begin{array}{l}252 \\
{[17000]}\end{array}$ & 0.25 & 251 & 0.23 & $\begin{array}{l}\text { HOMO-7 } \rightarrow \text { LUMO } \\
B_{3 u} \rightarrow B_{19}\end{array}$ & $\mathrm{~S} 3 \mathrm{p} \rightarrow \mathrm{O}^{*} \mathrm{~S}-\mathrm{Ni}$ \\
\hline $\begin{array}{l}316 \\
{[33000]}\end{array}$ & 0.58 & $\begin{array}{l}322 \\
331\end{array}$ & $\begin{array}{l}0.34 \\
0.28\end{array}$ & $\begin{array}{l}\text { HOMO- } 4 \rightarrow \text { LUMO } \\
B_{2 u} \rightarrow B_{1 g} \\
\text { HOMO-3 } \rightarrow \text { LUMO + } 2 \\
A_{u} \rightarrow B_{2 g}\end{array}$ & $\begin{array}{l}\mathrm{S} 3 \mathrm{p} \rightarrow \sigma^{*} \mathrm{~S}-\mathrm{Ni} \\
\mathrm{S} 3 \mathrm{p}_{\mathrm{z}} \rightarrow \pi^{*} \mathrm{OCS}_{2}\end{array}$ \\
\hline $\begin{array}{l}386 \\
\text { Shoulder }\end{array}$ & - & 363 & 0.03 & $\begin{array}{l}\text { HOMO-5 } \rightarrow \text { LUMO } \\
B_{3 g} \rightarrow B_{1 g}\end{array}$ & $\pi \mathrm{Ni}-\mathrm{S} \rightarrow \sigma^{*} \mathrm{~S}-\mathrm{Ni}$ \\
\hline $\begin{array}{l}414 \\
{[2750]}\end{array}$ & 0.03 & 411 & 0.04 & $\begin{array}{l}\text { HOMO-2 } \rightarrow \text { LUMO + } 1 \\
B_{2 g} \rightarrow B_{1 u}\end{array}$ & $\pi^{*} \mathrm{Ni}-\mathrm{S}_{2} \mathrm{CO} \rightarrow \pi^{*} \mathrm{OCS}_{2}$ \\
\hline $\begin{array}{l}474 \\
{[1500]}\end{array}$ & 0.01 & 481 & 0.02 & $\begin{array}{l}\mathrm{HOMO} \rightarrow \mathrm{LUMO}+1 \\
B_{3 g} \rightarrow B_{1 u}\end{array}$ & $\pi^{*} \mathrm{~S}-\mathrm{Ni} \rightarrow \pi^{*} \mathrm{OCS}_{2}$ \\
\hline $\begin{array}{l}638 \\
{[80]}\end{array}$ & - & 635 & 0.0002 & $\begin{array}{l}H O M O \rightarrow L U M O \\
B_{3 g} \rightarrow B_{1 g}\end{array}$ & $\pi^{*} \mathrm{~S}-\mathrm{Ni} \rightarrow \sigma^{*} \mathrm{~S}-\mathrm{Ni}$ \\
\hline
\end{tabular}

a Calculated from Eq. (1) (Experimental Section).

b Scaled using a nonlinear curve Fit (logistic model) $y=A_{2}+\left(A_{1}-A_{2}\right) /\left(1+\left(X . X_{0}^{-1}\right)^{p}\right)$, where $A_{1}=56, A_{2}=699, X_{0}=313$ and $p=2.5$ with an Adj. R-Square $=0.9915$.

c $\mathrm{A} \mathrm{D}_{2 \mathrm{~h}}$ local symmetry was considered for the assignment.

The maxima in the spectra correspond to electronic transition, which can be approximated as the energy difference between occupied valence molecular orbitals (HOMOs) and virtual unoccupied molecular orbitals (LUMOs). To help the interpretation and assignment of the electronic transitions, TD-DFT calculations with the B3LYP/6-31 + $\mathrm{G}^{*}$ approximation were performed. The optimized structure, obtained using the X-ray single crystal structure as input $[18,19]$, belongs to the $\mathrm{C}_{2}$ symmetry point group. However, and as presented below, the UVvisible spectra were interpreted trough electronic transitions involving molecular orbitals localized only in the $-\mathrm{OCS}_{2} \mathrm{NiS}_{2} \mathrm{CO}$ - moiety, which has a local symmetry that can be assumed as $\mathrm{D}_{2 \mathrm{~h}}$ (strictly in the computed structure there is a slight deviation from this symmetry since the nickel atom is not exactly in the plane formed by the four sulfur atoms). For this reason, the analysis of the symmetry of the molecular orbitals used for the interpretation of the electronic spectra was performed on the basis of the $D_{2 h}$ point group.

Fig. 2 shows a schematic representation of selected molecular orbitals of $\mathrm{Ni}\left(\mathrm{CH}_{3}\left(\mathrm{CH}_{2}\right)_{2} \mathrm{OC}(\mathrm{S}) \mathrm{S}\right)_{2}$, calculated with the TD-B3LYP/6$31+\mathrm{G}^{*}$ approximation, together with an approximate description and the symmetry of the orbitals. The calculated wavenumbers for the most relevant one-electron transitions are listed in Table 1, together with the theoretical oscillator strength $(f)$. The calculated UV-visible spectrum presents a very good agreement with the experimental ones, as can be observed in Fig. 3 .

An extremely weak absorption around $630 \mathrm{~nm}$, observed only at concentrations higher than $10^{-3} \mathrm{M}$, was assigned to the HOMO $\rightarrow$ LUMO transition, according with theoretical predictions. The HOMO, schematically represented in Fig. 2, can be approximately

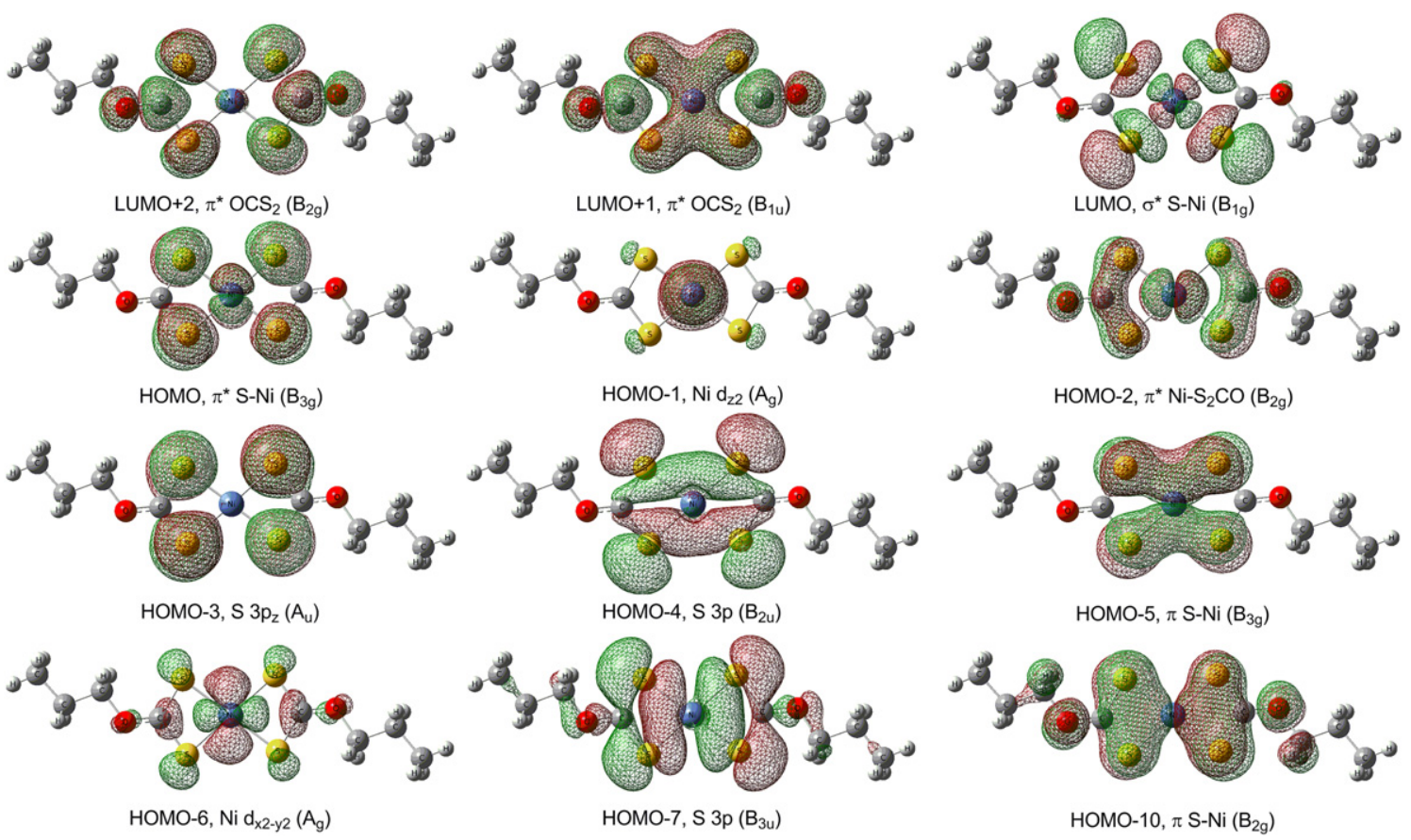

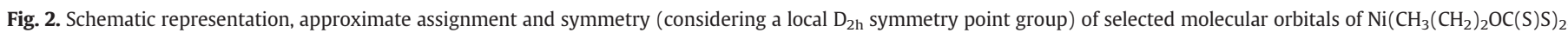
calculated with the TD-B3LYP/6-31 + G* approximation. 


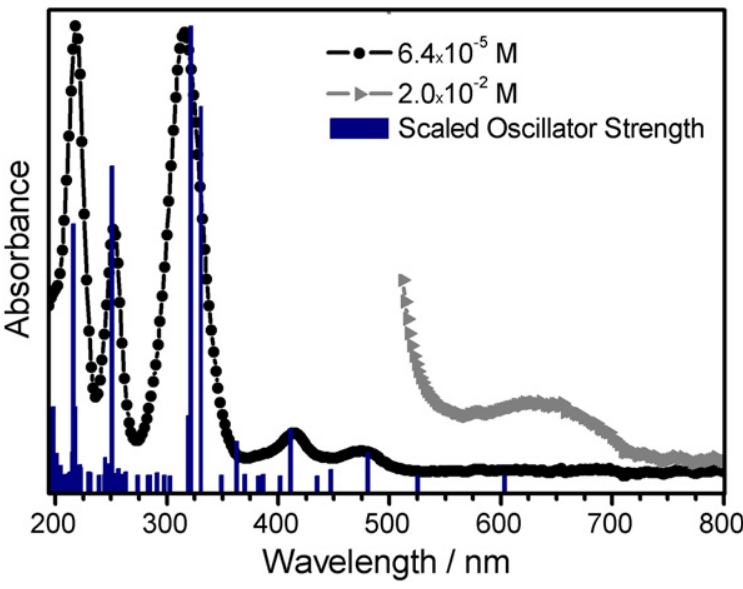

Fig. 3. Comparison of the experimental UV-visible spectrum of $\mathrm{Ni}\left(\mathrm{CH}_{3}\left(\mathrm{CH}_{2}\right)_{2} \mathrm{OC}(\mathrm{S}) \mathrm{S}\right)_{2}$ in $\mathrm{CH}_{3} \mathrm{CN}$ solution with the scaled one-electron transitions spectrum calculated with the TDB3LYP/6-31 + G* approximation.

described as $\pi^{*} \mathrm{~S}-\mathrm{Ni}$, composed by the $\mathrm{Ni} 3 \mathrm{~d}_{\mathrm{yz}}$ and $\mathrm{S} 3 \mathrm{p}_{\mathrm{z}}$ atomic orbitals of the ligands, with $\mathrm{B}_{3 \mathrm{~g}}$ symmetry in the frame of the $\mathrm{D}_{2 \mathrm{~h}}$ symmetry point group. The LUMO is associated with a $\sigma^{*} \mathrm{~S}-\mathrm{Ni}\left(\mathrm{B}_{1 \mathrm{~g}}\right)$, formed by the Ni $3 d_{x y}$ and the $S 3 p$ (in the direction of the $S-N i$ chemical bonds) atomic orbitals of the xanthate ligands. The $630 \mathrm{~nm}$ band can then be interpreted as $\pi^{*} \mathrm{~S}-\mathrm{Ni}\left(\mathrm{B}_{3 \mathrm{~g}}\right) \rightarrow \sigma^{*} \mathrm{~S}-\mathrm{Ni}\left(\mathrm{B}_{1 \mathrm{~g}}\right)$ transition, which is expected with very low intensity since it is symmetry forbidden in the $\mathrm{D}_{2 \mathrm{~h}}$ point group. The present description is also in agreement with previous works on related $\mathrm{Ni}$ (II) square planar complexes that assigned a similar absorption to a Laporte forbidden " $\mathrm{d} \rightarrow \mathrm{d}$ " transition $[43,44]$.

The second band in the experimental electronic spectra, occurring at $470 \mathrm{~nm}$ with a moderated intensity, was assigned to the

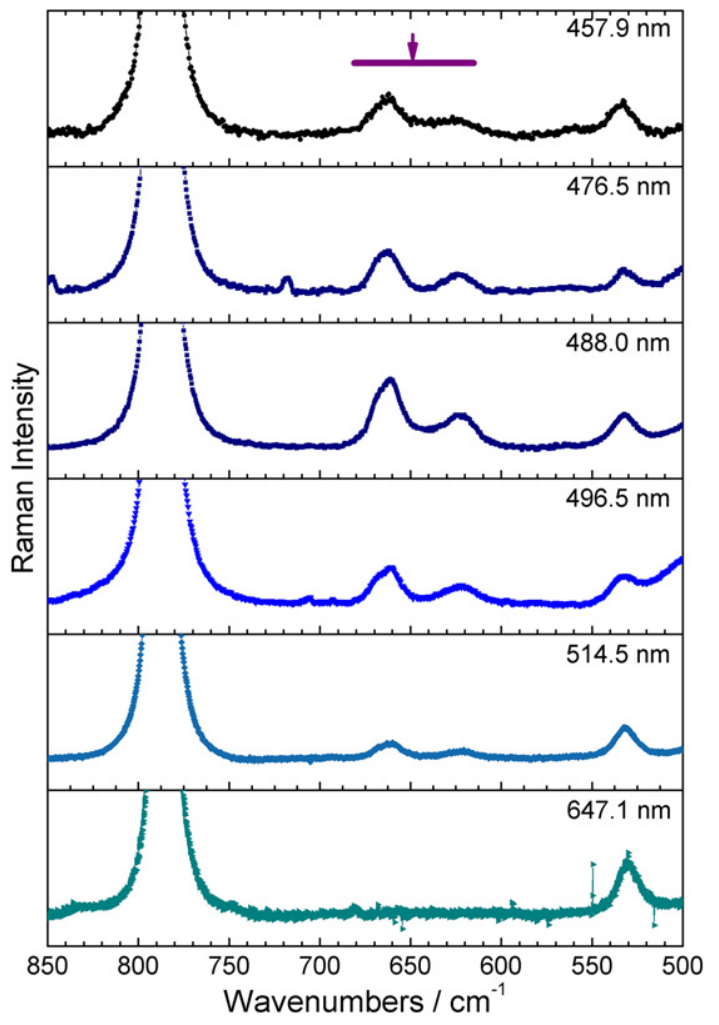

Fig. 4. Raman spectra of $\mathrm{Ni}\left(\mathrm{CH}_{3}\left(\mathrm{CH}_{2}\right)_{2} \mathrm{OC}(\mathrm{S}) \mathrm{S}\right)_{2}$ between 850 and $500 \mathrm{~cm}^{-1}$ excited with wavelengths between 647.1 and $457.9 \mathrm{~nm}$, normalized with respect to the $788 \mathrm{~cm}^{-1}$ band of the solvent (acetone).

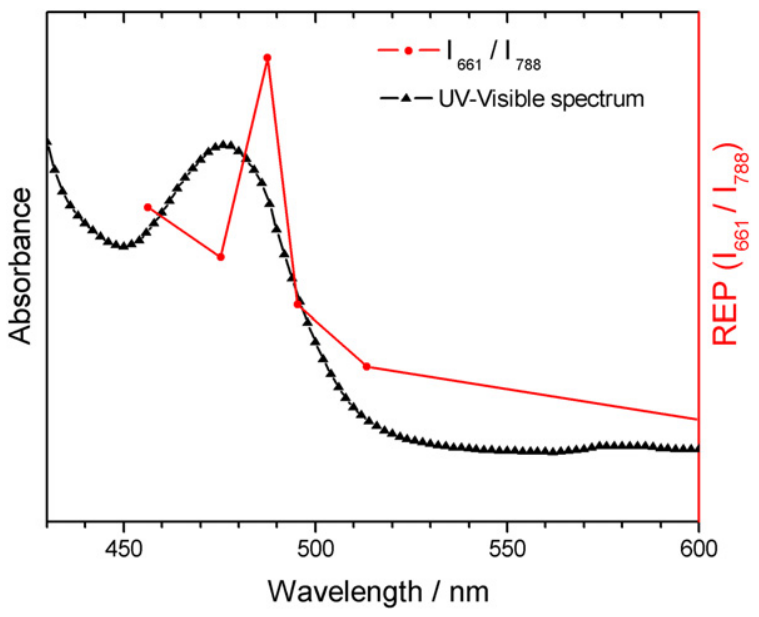

Fig. 5. UV-visible spectrum (black trace) and Raman excitation profile of $v_{s}(S-C=S)$ normalized with respect to the $788 \mathrm{~cm}^{-1}$ Raman band of acetone (red trace) of $\mathrm{Ni}\left(\mathrm{CH}_{3}\left(\mathrm{CH}_{2}\right)_{2} \mathrm{OC}(\mathrm{S}) \mathrm{S}\right)_{2}$ in acetone solution.

$\mathrm{HOMO} \rightarrow \mathrm{LUMO}+1$ transition. As depicted in Fig. 2 , the LUMO +1 is composed by the $S 3 p_{z}, C 2 p_{z}$, and $O 2 p_{z}$ atomic orbitals of the xanthate ligands, forming a $\pi^{*} \mathrm{OCS}_{2}$ molecular orbital, with a $\mathrm{B}_{1 \mathrm{u}}$ symmetry. This absorption can then be described as an allowed $\pi^{*} \mathrm{~S}-\mathrm{Ni}$ $\left(\mathrm{B}_{3 \mathrm{~g}}\right) \rightarrow \pi^{*} \mathrm{OCS}_{2}\left(\mathrm{~B}_{1 \mathrm{u}}\right)$, and interpreted as a metal to ligand charge transfer (MLCT) band. The next absorption, at $415 \mathrm{~nm}$, is proposed to arise from the HOMO- $\rightarrow$ LUMO +1 transition. The Ni $d_{x z}, S 3 p_{z}, C 2 p_{z}$, and $\mathrm{O} 2 \mathrm{p}_{\mathrm{z}}$ atomic orbitals are combined in a $\pi^{*} \mathrm{Ni}-\mathrm{S}_{2} \mathrm{CO}$ (HOMO-2) molecular orbital with $\mathrm{B}_{2 \mathrm{~g}}$ symmetry. This transition, $\pi^{*} \mathrm{Ni}-\mathrm{S}_{2} \mathrm{CO}$ $\left(\mathrm{B}_{2 \mathrm{~g}}\right) \rightarrow \pi^{*} \mathrm{OCS}_{2}\left(\mathrm{~B}_{1 \mathrm{u}}\right)$, can also be classify as MLCT band.

The most intense absorption in the UV-visible spectra, at $316 \mathrm{~nm}$, can be originated by two symmetry allowed electronic transitions

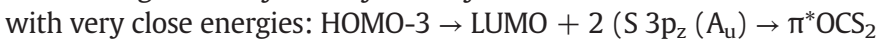
$\left(\mathrm{B}_{2 \mathrm{~g}}\right)$ ) and HOMO-4 $\rightarrow$ LUMO $\left(\mathrm{S} 3 \mathrm{p}\left(\mathrm{B}_{2 \mathrm{u}}\right) \rightarrow \sigma^{*} \mathrm{~S}-\mathrm{Ni}\left(\mathrm{B}_{1 \mathrm{~g}}\right)\right.$ transitions). The $S 3 p$ atomic orbitals of the ligands that conform the HOMO-4 are the ones focused on the direction of the S-Ni bond, as in the case of the LUMO. The last two bands, at 252 and $218 \mathrm{~nm}$, were assigned to the symmetry allowed HOMO-7 $\rightarrow$ LUMO $\left(\mathrm{S} 3 \mathrm{p}\left(\mathrm{B}_{3 \mathrm{u}}\right) \rightarrow \mathrm{o}^{*} \mathrm{~S}-\mathrm{Ni}\left(\mathrm{B}_{1 \mathrm{~g}}\right)\right)$ transition, that corresponds to a LMCT, and HOMO-10 $\rightarrow$ LUMO +1 $\left(\pi \mathrm{S}-\mathrm{Ni}\left(\mathrm{B}_{2 \mathrm{~g}}\right) \rightarrow \pi^{*} \mathrm{OCS}_{2}\left(\mathrm{~B}_{1 \mathrm{u}}\right)\right)$, respectively. As depicted in Fig. 2, HOMO-10 has contributions of $S 3 \mathrm{p}_{\mathrm{z}}$ and $\mathrm{Ni} \mathrm{d}_{\mathrm{xz}}$ atomic orbitals, with a minor component of $\mathrm{O} 2 \mathrm{p}_{\mathrm{z}}$ orbitals.

The interpretation and assignment of the UV-visible spectra of $\mathrm{Ni}\left(\mathrm{CH}_{3}\left(\mathrm{CH}_{2}\right)_{2} \mathrm{OC}(\mathrm{S}) \mathrm{S}\right)_{2}$ complex described in the precedent paragraphs, and resumed in Table 1 , is in complete agreement with the qualitative description of the UV-visible spectra of related $\mathrm{Ni}$ (II) complexes previously studied $[38,45,46]$. As will be explained in the Conclusion Section, this schematic and simplified interpretation of the UV-visible spectra in

Table 2

Binding energies (in eV) of internal electrons of $\mathrm{Ni}\left(\mathrm{CH}_{3}\left(\mathrm{CH}_{2}\right)_{2} \mathrm{OC}(\mathrm{S}) \mathrm{S}\right)_{2}$.

\begin{tabular}{lll}
\hline $\mathrm{E}_{\mathrm{b}}[\mathrm{eV}]$ & Assignment & $\mathrm{E}_{\mathrm{b}}{ }^{\mathrm{a}}$ \\
\hline 860 & Ni 2p $1 / 2$ & 870.0 \\
& Ni 2p 3/2 & 852.7 \\
531 & O 1s & 543.1 \\
- & K 2s & 378.6 \\
300 & C 1s shake up & \\
282 & C 1s & 284.2 \\
224 & S 2s & 230.9 \\
160 & S 2p 1/2 & 163.6 \\
& S 2p 3/2 & 162.5 \\
109 & Ni 3s & 110.8 \\
65 & Ni 3p $1 / 2$ & 68.0 \\
& Ni 3p 3/2 & 66.2 \\
\hline
\end{tabular}

${ }^{a}$ Binding energy $\left(E_{b}, e V\right)$ of the elements in their natural state from reference [55]. 


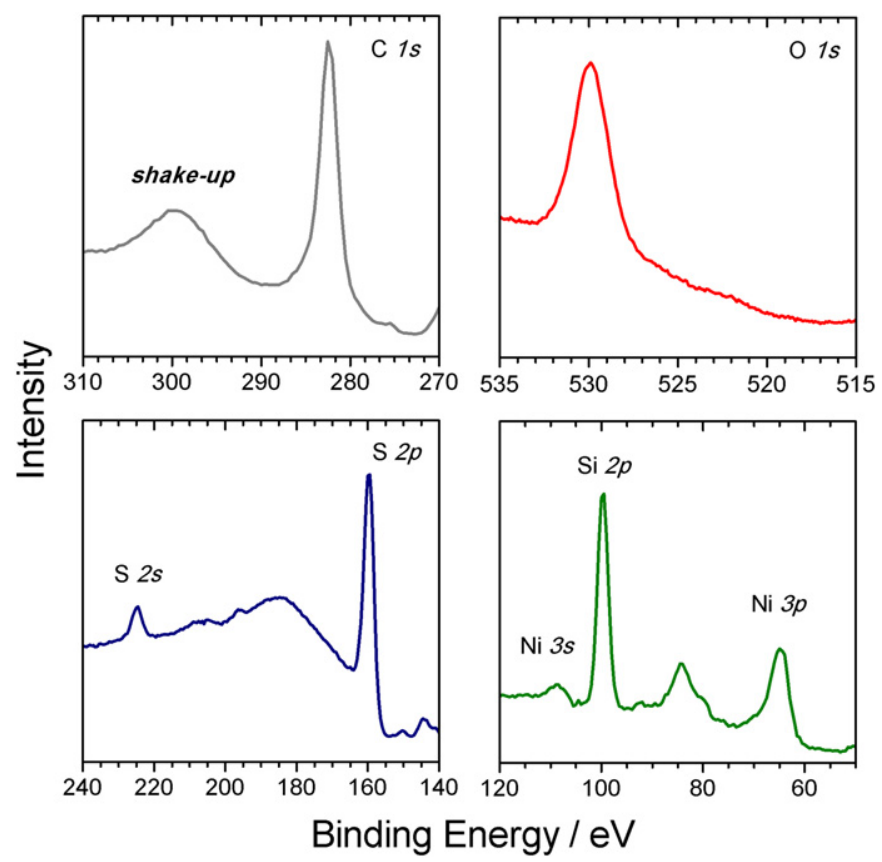

Fig. 6. Photoelectron spectra corresponding to the C $1 \mathrm{~s}$ (310-270 eV, grey), O 1s (535$515 \mathrm{eV}$, red), S 2s and S 2p (240-150 eV, blue) and Ni 3s and Ni 3p (120-50 eV, green) electrons of $\mathrm{Ni}\left(\mathrm{CH}_{3}\left(\mathrm{CH}_{2}\right)_{2} \mathrm{OC}(\mathrm{S}) \mathrm{S}\right)_{2}$.

terms of molecular orbitals transitions allows the experimental determination of the energy differences between some of the involved orbitals.

\subsection{Resonance Raman Spectroscopy}

The Resonance Raman spectroscopy combines vibrational and electronic spectroscopies. If the Raman spectrum is taken with an excitation energy that coincides with or approximates to the corresponding energy of an electronic transition, the vibrational modes associated with the excited state are enhanced. This univocal correspondence can then be used as a useful assignment criterion, either for the electronic transition if the vibrational assignment is known with confidence, or for the identification of the vibrational mode in the case of a clearly assigned electronic transition.

In the present work, the resonance Raman excitation profile of $\mathrm{Ni}\left(\mathrm{CH}_{3}\left(\mathrm{CH}_{2}\right)_{2} \mathrm{OC}(\mathrm{S}) \mathrm{S}\right)_{2}$ in acetone solutions, with excitation energies between 647.1 and $457.9 \mathrm{~nm}$, was determined. Prior to the analysis of the resonance Raman spectra, a traditional vibration study (including FTIR and FTRaman of the solid sample) was performed, in order to assign the bands to the vibrational modes. Fig. S1 of the Supplementary Information shows the FTIR and Raman spectra and Table S2 lists the FTIR and FTRaman wavenumbers observed in the spectra, together with the predicted values calculated with the B3LYP/6-31 + G* approximation, and a tentative assignment, performed mainly with the aid of the theoretical calculations and the usual comparison with related species [38, 47-50].

Fig. 4 depicts a selected region of the Raman spectra of the complex in an acetone solution, used as internal standard, measured with 647.1, $514.5,496.5,488.0,476.5$ and $457.9 \mathrm{~nm}$ excitation energies. In the Raman spectrum taken with radiation of $647.1 \mathrm{~nm}$, only bands of the solvent can be observed. As the energy of the radiation increases, two new bands, at approximately 661 and $619 \mathrm{~cm}^{-1}$, become discernable. The peak at $661 \mathrm{~cm}^{-1}$ is assigned, according to the vibrational analysis presented in the Supplementary Information, to the $v_{s}(\mathrm{SCS})_{i . p}$ vibrational mode, that belongs to the totally symmetric representation of the chromophore if the $\mathrm{D}_{2 \mathrm{~h}}$ local symmetry is considered. The Raman excitation profile of this mode (the plot of the intensity of the band with respect to the intensity of a band of a standard as a function of the excitation energy) depicted in Fig. 5, clearly follows the shape of the electronic UV-visible spectrum. This experimental finding confirms the assignment of the $476 \mathrm{~nm}$ electronic band to a transition to an empty molecular orbital localized on the $-\mathrm{CS}_{2}$ group (see Table 1 and Fig. 2).

The band at $619 \mathrm{~cm}^{-1}$, that approximately presents the same behavior than the $v_{s}(\mathrm{SCS})_{i . p}$ vibrational mode, does not correspond to a fundamental vibration (see Table S2). It is well known that in resonance Raman conditions, the non fundamental bands are intensified by an enhancement factor that approximately correspond to the multiplication of the enhancement factors of the fundamentals. For this reason, overtone and combination bands are more intense in resonance Raman spectra that in "normal" Raman spectra (see, for example, reference [51]). The band at $619 \mathrm{~cm}^{-1}$ was then assigned to a combination mode of $v_{a s}(\mathrm{SNiS})_{\text {i.p. }}\left(\mathrm{B}_{1 \mathrm{~g}}\right)$ and $\delta(\mathrm{SCS})_{\text {i.p. }}\left(\mathrm{A}_{\mathrm{g}}\right)$, also associated with the electronic transition in the chomophore.

\subsection{Photoelectron Spectroscopy (PES)}

Table 2 lists the values of binding energies of the inner shells electrons (in eV) for the nickel complex (calculated using Eq. (2) of the Experimental Section). In the photoelectron spectra corresponding to the ionization of the $C$ 1s electrons, two signals can be observed (see Fig. 6). The first one, around $282 \mathrm{eV}$, was assigned to the $\mathrm{C} 1 \mathrm{~s}$ electrons of all carbon atoms present in the complex. The second signal, near $300 \mathrm{eV}$, is a weak broadband that was assigned to a shake-up satellite of the $\mathrm{C} 1 \mathrm{~s}$. The region of ionization of $\mathrm{O}$ 1s electrons shows only one signal. The signal due to the $S 2 \mathrm{p}$ electrons appears as a broad band that fails to resolve the expected doublet caused by the spin-orbit coupling [52]. The signals due to ionization of 3s (109 eV) and 3p (65 eV) electrons of the nickel atom were also observed in Fig. 6. The binding energies listed in Table 2 are similar to those reported previously for potassium ethyl xanthate, sodium isopropylxanthate, and various nickel (II) complexes with $-\mathrm{OCS}_{2}$ - group containing ligands [53,54].

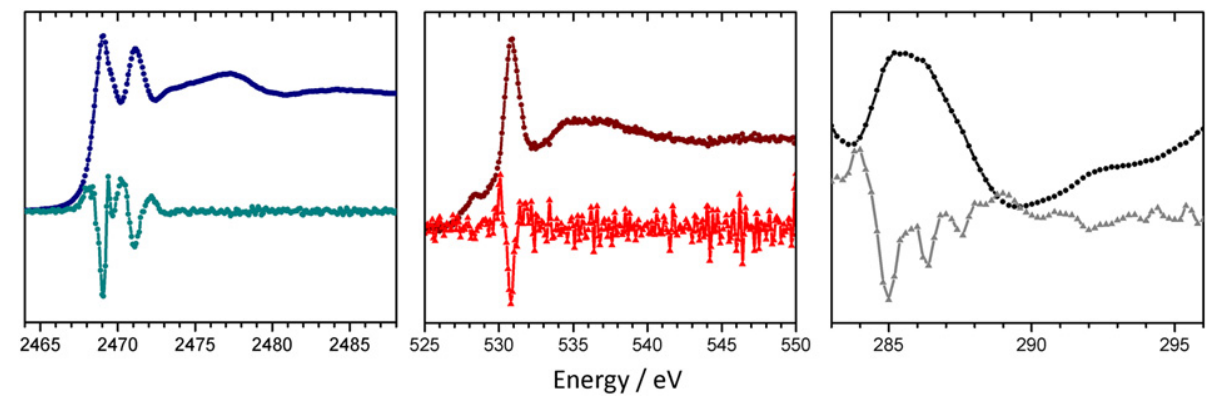

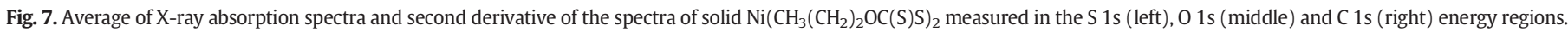




\subsection{X-ray Absorption Near Edge Structure (XANES) Spectroscopy}

The XANES spectra are characterized by resonances arising from the excitation of core or inner-shell electrons to low energy unoccupied molecular orbitals. For such transitions the rule $\Delta \mathrm{L}= \pm 1$ become operative. Therefore, only molecular orbitals with p character $(L=1)$ obey the rule when 1 s core electrons $(\mathrm{L}=0)$ are excited by resonant $\mathrm{X}$-ray absorption.

The average of ten XANES spectra measured in the region of excitation of $\mathrm{S} 1 \mathrm{~s}(\mathrm{~K})$ electrons is shown in Fig. 7, together with the corresponding second derivative of the spectra. The presence of three preionization threshold resonances, at 2469.1, 2469.7, and $2471.1 \mathrm{eV}$, can be clearly observed in the figure. A forth peak, close to $2473.3 \mathrm{eV}$, seems also be present.

In the case of a transition metal complex with sulfur-containing ligands, the $S 3$ p orbitals are directly involved in the bonds with the transition metal ions, $\mathrm{M}_{3 \mathrm{~d}}-\mathrm{S}_{3 \mathrm{p}}$, so the $\mathrm{S}$ 1s XANES spectra provides a direct probe of the ligand-metal interactions. The observed intensity of these transitions is proportional to the fraction of $\mathrm{S} 3 \mathrm{p}$ orbitals in the empty antibonding molecular orbitals, and was proposed to provide direct evidence of the ligand contribution to the antibonding empty or partially occupied orbitals [56-60]. In previous reports, the interpretation of the resonances in the region of excitation of $\mathrm{S} 1 \mathrm{~s}$ electrons was aided by the use of several theoretical calculation, as for example DFT, TDDFT, NPA, AIM methods, among others [56,61-63].

In the present study, a plausible interpretation of the resonances, based mainly in the results of the TD-DTF calculation presented previously, can be through transitions from S $1 \mathrm{~s}$ orbital to LUMO ( $\left.\sigma^{*} \mathrm{~S}-\mathrm{Ni}\right)$, $\mathrm{LUMO}+1\left(\pi^{*} \mathrm{OCS}_{2}\right)$, and LUMO $+2\left(\pi^{*} \mathrm{OCS}_{2}\right)$, respectively. As depicted in Fig. 2, the 3p S atomic orbitals significantly contribute to these three LUMOs. The proposed assignment is reinforced if the $0.6 \mathrm{eV}$ energy difference between LUMO and LUMO + 1 obtained from the $S 1$ s XANES spectra is compared with the $0.7 \mathrm{eV}$ energy difference observed for the same pair of molecular orbital in the UV-visible spectra. Taking into account the experimental uncertainties in the determination of the XANES maxima, we can conclude that these two values are in complete agreement. An energy difference of $2.0 \mathrm{eV}$ between LUMO and LUMO +2 can also be calculated from the $S 1$ s XANES spectra.

The $01 \mathrm{~s}(\mathrm{~K})$ XANES spectrum of the complex is depicted in Fig. 7. After deconvolution of the spectrum, three resonances at 528.4, approximately 529.7, and $530.9 \mathrm{eV}$ can be determined below the ionization potential of the 01 s electrons. The first two resonances, with similar intensities, were assigned to $\mathrm{O} 1 \mathrm{~s} \rightarrow \mathrm{LUMO}+1\left(\pi^{*} \mathrm{OCS}_{2}\right)$ and $\mathrm{O} 1 \mathrm{~s} \rightarrow \mathrm{LUMO}+2\left(\pi^{*} \mathrm{OCS}_{2}\right)$ transitions, respectively, with the aid of theoretical calculations. The approximate $1.3 \mathrm{eV}$ energy difference between LUMO +1 and LUMO +2 obtained from this spectrum agrees fairly well with the $\Delta \mathrm{E}=1.4 \mathrm{eV}$ found in the $\mathrm{S} 1 \mathrm{~s}$ XANES spectra for this two MOs. The third transition is assigned to the promotion of the $01 \mathrm{~s}$ electron to LUMO + 3, a molecular orbital that can be described, according with theoretical calculations, as entirely delocalized over the whole complex, with contributions of the $\mathrm{O} 2 \mathrm{p}, \mathrm{C} 2 \mathrm{p}$ and $\mathrm{Ni} 3 \mathrm{~d}$ AOs.

Three resonance signals can be observed below the ionization potential of the C 1s (K) electrons, at 285.0, 286.4, and $287.6 \mathrm{eV}$ (see Fig. 7). According with the predicted character of the LUMOs, these resonances can be assigned to transitions from $C 1$ s to LUMO +1 , LUMO +2 , and LUMO +3 . The experimental energy differences between these molecular orbital are coincident with the obtained from the 0 1s XANES spectrum described previously, giving confidence to the proposed assignment.

The averaged XANES spectra of $\mathrm{Ni}\left(\mathrm{CH}_{3}\left(\mathrm{CH}_{2}\right)_{2} \mathrm{OC}(\mathrm{S}) \mathrm{S}\right)_{2}$ in the excitation region of the core $\mathrm{Ni}(\mathrm{K})$ 1s electrons are presented in Fig. 8. From the second derivative of the spectra, also shown in the figure, two resonances at 8328.9 and $8333.1 \mathrm{eV}$ can be discerned. The first band, with very low intensity, was readily attributed to the symmetry forbidden $\mathrm{Ni} 1 \mathrm{~s} \rightarrow \sigma^{*} \mathrm{~S}-\mathrm{Ni}$ transition, according to previous studies on nickel (II) salts and complexes, that assigned a pre-edge low-intensity resonance
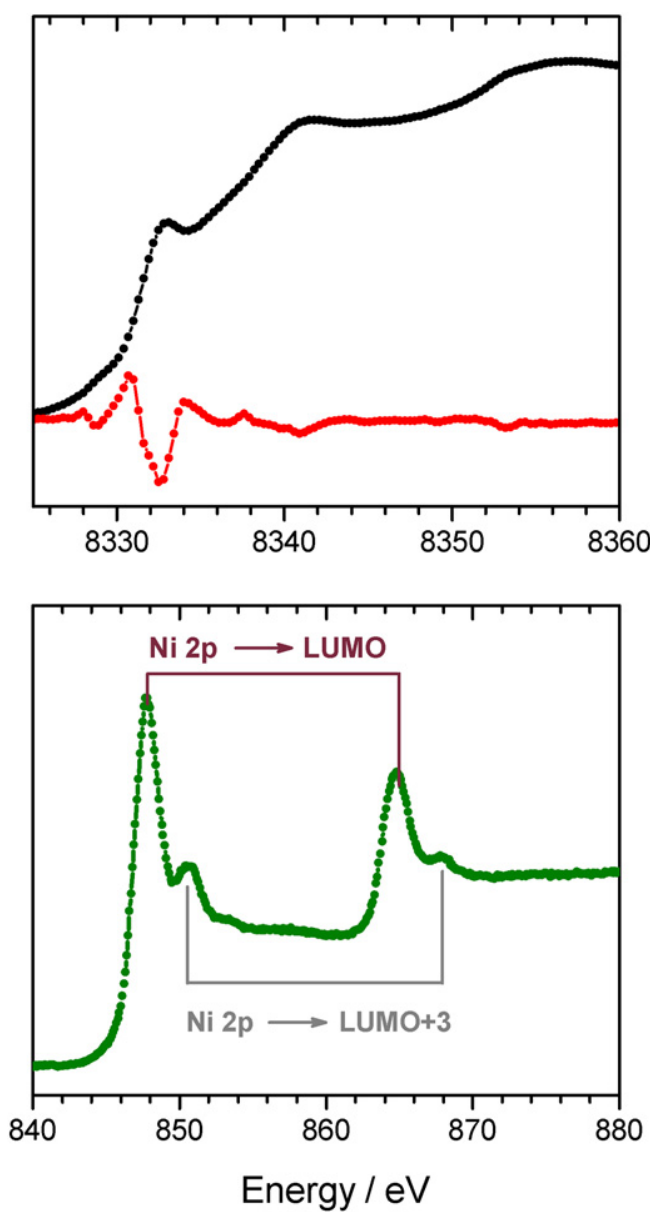

Fig. 8. Average of five XANES spectra and second derivative of the spectra of solid $\mathrm{Ni}\left(\mathrm{CH}_{3}\left(\mathrm{CH}_{2}\right)_{2} \mathrm{OC}(\mathrm{S}) \mathrm{S}\right)_{2}$ measured in the $\mathrm{Ni}$ 1s energy region (top) and of ten XANES spectra in the Ni $2 p$ energy region (bottom).

to a Ni 1s $\rightarrow$ Ni 3d transition (from a Ni 1s atomic orbital to unoccupied antibonding orbitals with Ni 3d character) $[64,65]$.

The second and most intense band, at $8332.6 \mathrm{eV}$, should arise from an allowed $\mathrm{Ni} 1 \mathrm{~s} \rightarrow \mathrm{Ni} 4 \mathrm{p}$ transition, referred as "white line" in the literature $[64,65]$. This transition was tentatively assigned to a promotion of a Ni 1 s electron to LUMO + 4, which is predicted with an important contribution of $\mathrm{Ni} 4 \mathrm{p}$ atomic orbitals, combined with S 3p orbitals. According with this proposed assignment, an energy difference of $3.7 \mathrm{eV}$ between LUMO and LUMO +4 can be calculated from the spectra depicted in Fig. 8. A very low intensity resonance in the $S$ 1s XANES spectra (see Fig. 7) presents also the same energy difference with the $\mathrm{S} 1 \mathrm{~s} \rightarrow \sigma^{*} \mathrm{~S}-\mathrm{Ni}$ transition, which allow us to propose that this peak, at about $2473.3 \mathrm{eV}$, can be assigned to a S $1 \mathrm{~s} \rightarrow$ LUMO +4 transition.

The XANES spectra of the Ni L-edge energy region were also measured, and are presented in Fig. 8. Two pair of bands at 847.7/850.6 and $864.8 / 867.8 \mathrm{eV}$, with similar shapes and relative intensities, are observed in the spectra. The L edge XANES spectra of nickel compounds are composed by two signals due to spin-orbit coupling, $\mathrm{L}_{3}\left(2 \mathrm{p}_{3 / 2}\right)$ and $\mathrm{L}_{2}\left(2 \mathrm{p}_{1 / 2}\right)$, with a separation of $16 \mathrm{eV}$ for $\mathrm{Ni}(0)[66,67]$. In the present case the pair of bands are separated by $17.1 / 17.2 \mathrm{eV}$, and with relative intensities close to 2 , indicating that corresponds to $\mathrm{L}_{3}$ and $\mathrm{L}_{2}$ transitions, respectively. According to the $\Delta \mathrm{L}= \pm 1$ selection rule, $2 \mathrm{p}^{6}$ $3 \mathrm{~d}^{8} \rightarrow 2 \mathrm{p}^{5} 3 \mathrm{~d}^{9}$ allowed transitions are expected to present the highest intensities. On the other hand, $2 \mathrm{p} \rightarrow 4 \mathrm{~s}$ transitions also allowed by the dipole selection rule, have in general only about $1 / 30$ of the intensity of the $2 \mathrm{p} \rightarrow 3 \mathrm{~d}$ transitions [68].

The resonances at 847.7 and $864.8 \mathrm{eV}$ were then assigned to the $\mathrm{L}_{3}$ and $\mathrm{L}_{2}$ components of transitions from Ni $2 \mathrm{p}$ AOs to the LUMO 
Table 3

Energy (eV) and proposed assignment of the resonances observed in XANES spectra of $\mathrm{Ni}\left(\mathrm{CH}_{3}\left(\mathrm{CH}_{2}\right)_{2} \mathrm{OC}(\mathrm{S}) \mathrm{S}\right)_{2}$.

\begin{tabular}{ll}
\hline Energy/eV & Tentative assignment \\
\hline 8333.1 & Ni $1 \mathrm{~s} \rightarrow$ LUMO +4 \\
8328.9 & Ni $1 \mathrm{~s} \rightarrow$ LUMO \\
2473.3 & $\mathrm{~S} 1 \mathrm{~s} \rightarrow$ LUMO +4 \\
2471.1 & $\mathrm{~S} 1 \mathrm{~s} \rightarrow$ LUMO +2 \\
2469.7 & $\mathrm{~S} 1 \mathrm{~s} \rightarrow$ LUMO +1 \\
2469.1 & $\mathrm{~S} 1 \mathrm{~s} \rightarrow$ LUMO \\
867.8 & Ni $2 \mathrm{p} \rightarrow$ LUMO $+3\left(\mathrm{~L}_{2}\right)$ \\
864.8 & Ni $2 \mathrm{p} \rightarrow$ LUMO $\left(\mathrm{L}_{2}\right)$ \\
850.6 & Ni $2 \mathrm{p} \rightarrow$ LUMO $+3\left(\mathrm{~L}_{3}\right)$ \\
847.7 & Ni $2 \mathrm{p} \rightarrow$ LUMO $\left(\mathrm{L}_{3}\right)$ \\
530.9 & O $1 \mathrm{~s} \rightarrow$ LUMO +3 \\
529.7 & O $1 \mathrm{~s} \rightarrow$ LUMO +2 \\
528.4 & O $1 \mathrm{~s} \rightarrow$ LUMO +1 \\
287.6 & C $1 \mathrm{~s} \rightarrow$ LUMO +3 \\
286.4 & C $1 \mathrm{~s} \rightarrow$ LUMO +2 \\
285.0 & C $1 \mathrm{~s} \rightarrow$ LUMO +1 \\
\hline
\end{tabular}

( $\sigma^{*} \mathrm{~S}-\mathrm{Ni}$ ), composed by the $\mathrm{Ni} \mathrm{d}_{\mathrm{xy}} \mathrm{AO}$. The bands at 850.6 and $867.8 \mathrm{eV}$ were attributed to the $\mathrm{L}_{3}$ and $\mathrm{L}_{2}$ branches of the transitions to LUMO +3 , which presents contributions of the $\mathrm{O} 2 \mathrm{p}, \mathrm{C} 2 \mathrm{p}$ and $\mathrm{Ni} 3 \mathrm{~d}$ AOs. This assignment gives an energy difference between LUMO and LUMO +3 of $2.9\left(\mathrm{~L}_{3}\right)$ or $3.0\left(\mathrm{~L}_{2}\right) \mathrm{eV}$, in very good agreement with the $\triangle \mathrm{E}$ obtained from the other XANES spectra described previously. Table 3 compiles the energies of all the XANES resonances, together with a tentative assignment of the transitions.

An earlier study of the electronic structure of complexes with square planar geometry around a nickel central atom, including the $\mathrm{Ni}\left(\mathrm{CH}_{3} \mathrm{CH}_{2} \mathrm{OC}(\mathrm{S}) \mathrm{S}\right)_{2}$ complex [69], has reported experimental results that are comparable with the obtained in the present work. However, the authors considered a square planar symmetry for the complex, arriving to a different assignment.
XANES

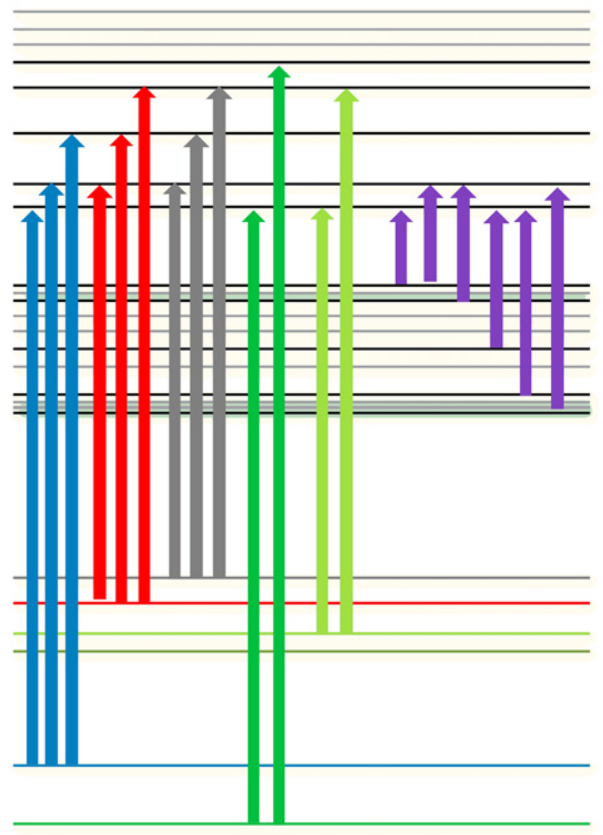

LUMO + 4 LUMO + 3

LUMO + 2

LUMO + 1

LUMO

номо

HOMO - 2

нОМо - 5

нОМо - 7

HOMO - 10

C 1s

01 s

Ni $2 p$

Ni 2s

S1s

Ni 1s
Fig. 9. Schematic energy level diagram scheme of $\mathrm{Ni}\left(\mathrm{CH}_{3}\left(\mathrm{CH}_{2}\right)_{2} \mathrm{OC}(\mathrm{S}) \mathrm{S}\right)_{2}$ showing the electronic transitions extracted from UV-visible and XANES spectra.
Table 4

Selected experimental molecular orbital energy differences (in $\mathrm{eV}$ ) extracted from the UV-Vis and XANES spectra of $\mathrm{Ni}\left(\mathrm{CH}_{3}\left(\mathrm{CH}_{2}\right)_{2} \mathrm{OC}(\mathrm{S}) \mathrm{S}\right)_{2}$.

\begin{tabular}{|c|c|c|}
\hline & $\begin{array}{l}\text { Experimental } \\
\text { energy } \\
\text { difference/eV }\end{array}$ & Spectroscopy \\
\hline \multirow[t]{2}{*}{$($ LUMO + 4) - (LUMO) } & 4.2 & XANES (Ni 1s) \\
\hline & 4.2 & XANES (S 1s) \\
\hline \multirow[t]{2}{*}{$($ LUMO + 3) - (LUMO + 2) } & 1.2 & XANES (0 1s) \\
\hline & 1.2 & XANES (C 1s) \\
\hline \multirow{2}{*}{$($ LUMO + 3) $-($ LUMO + 1) } & 2.5 & XANES (O 1s) \\
\hline & 2.6 & XANES (C 1s) \\
\hline \multirow[t]{3}{*}{$($ LUMO + 2) - (LUMO + 1) } & 1.4 & XANES (S 1s) \\
\hline & 1.3 & XANES (0 1s) \\
\hline & 1.4 & XANES (C 1s) \\
\hline \multirow[t]{2}{*}{$($ LUMO + 3) - (LUMO) } & 2.9 & XANES $\left(\mathrm{Ni} 2 \mathrm{p}_{3 / 2}\right)$ \\
\hline & 3.0 & XANES $\left(\mathrm{Ni} 2 \mathrm{p}_{1 / 2}\right)$ \\
\hline$($ LUMO + 2) - (LUMO) & 2.0 & XANES (S 1s) \\
\hline \multirow[t]{2}{*}{$($ LUMO + 1) - (LUMO) } & 0.7 & UV-Vis \\
\hline & 0.6 & XANES (S 1s) \\
\hline$($ LUMO + 1) - (HOMO) & 2.6 & UV-Vis \\
\hline$(\mathrm{LUMO})-(\mathrm{HOMO})$ & 1.9 & UV-Vis \\
\hline$($ LUMO + 1) - (HOMO-2) & 3.0 & UV-Vis \\
\hline (LUMO) - (HOMO-5) & 3.2 & UV-Vis \\
\hline (LUMO) - (HOMO-7) & 4.9 & UV-Vis \\
\hline$($ LUMO + 1) - (HOMO-10) & 5.7 & UV-Vis \\
\hline$(\mathrm{C} 1 \mathrm{~s})-\left(\mathrm{Ni} 2 \mathrm{p}_{1 / 2}\right)$ & 580.2 & XANES (Ni 2p $\left.\mathrm{p}_{1 / 2} / \mathrm{C} 1 \mathrm{~s}\right)$ \\
\hline$(\mathrm{C} 1 \mathrm{~s})-\left(\mathrm{Ni} 2 \mathrm{p}_{3 / 2}\right)$ & 563.0 & XANES (Ni 2p $3 / 2 / \mathrm{C} 1 \mathrm{~s})$ \\
\hline$(\mathrm{O} 1 \mathrm{~s})-\left(\mathrm{Ni} 2 \mathrm{p}_{1 / 2}\right)$ & 336.9 & XANES (Ni $\left.2 \mathrm{p}_{1 / 2} / \mathrm{O} 1 \mathrm{~s}\right)$ \\
\hline$(\mathrm{O} 1 \mathrm{~s})-\left(\mathrm{Ni} 2 \mathrm{p}_{3 / 2}\right)$ & 319.7 & XANES (Ni $\left.2 \mathrm{p}_{3 / 2} / \mathrm{O} 1 \mathrm{~s}\right)$ \\
\hline$(\mathrm{C} 1 \mathrm{~s})-(\mathrm{O} 1 \mathrm{~s})$ & 243.4 & XANES (O 1s/C 1s) \\
\hline (C 1s) - (S 1s) & 2184.7 & XANES (S 1s/C 1s) \\
\hline$(0$ 1s) - (S 1s) & 1941.3 & XANES (S 1s/O 1s) \\
\hline$\left(\mathrm{Ni} 2 \mathrm{p}_{3 / 2}\right)-(\mathrm{S} 1 \mathrm{~s})$ & 1621.4 & XANES (S 1s/Ni 2p $\mathrm{p}_{3 / 2}$ ) \\
\hline$\left(\mathrm{Ni} 2 \mathrm{p}_{1 / 2}\right)-(\mathrm{S} 1 \mathrm{~s})$ & 1604.3 & XANES (S 1s/Ni 2 $\mathrm{p}_{3 / 2}$ ) \\
\hline$\left(\mathrm{Ni} 2 \mathrm{p}_{3 / 2}\right)-(\mathrm{Ni} 1 \mathrm{~s})$ & 7481.2 & XANES (Ni 1s/Ni $2 \mathrm{p}_{3 / 2}$ ) \\
\hline$\left(\mathrm{Ni} 2 \mathrm{p}_{1 / 2}\right)-(\mathrm{Ni} 1 \mathrm{~s})$ & 7464.1 & XANES (Ni 1s/Ni 2 $\mathrm{p}_{3 / 2}$ ) \\
\hline$(\mathrm{S} 1 \mathrm{~s})-(\mathrm{Ni} 1 \mathrm{~s})$ & 5859.8 & XANES (Ni 1s/S 1s) \\
\hline$(\mathrm{HOMO})-(\mathrm{Ni} 1 \mathrm{~s})$ & 8328.9 & XANES (Ni 1s) \\
\hline
\end{tabular}

\section{Conclusions}

Fig. 9 schematically summarizes the construction of an energy level diagram through the assigned electronic transitions in the UVvisible and $\mathrm{Ni} 1 \mathrm{~s}, \mathrm{~S} 1 \mathrm{~s}, \mathrm{Ni} 2 \mathrm{p}, \mathrm{O} 1 \mathrm{~s}$ and $\mathrm{C} 1 \mathrm{~s}$ XANES spectra of $\mathrm{Ni}\left(\mathrm{CH}_{3}\left(\mathrm{CH}_{2}\right)_{2} \mathrm{OC}(\mathrm{S}) \mathrm{S}\right)_{2}$, described previously in this paper. From the energy differences of two transitions either from the same initial MO to a different final $\mathrm{MO}$ or from a different initial $\mathrm{MO}$ to a same final MO, a quantitative molecular orbital diagram can be constructed. Table 4 lists some selected energy differences between valence, inner and core molecular orbitals. As can be appreciated in the table, the values are at most within $0.1 \mathrm{eV}$ between different spectroscopies.

The results presented here constitutes a quite remarkable example of the combination, like a puzzle, of a set of robust conventional and innovative experimental techniques - UV-visible, resonance Raman, PES and XANES spectroscopies - together with TD-DFT methods, for the study of the electronic structure of a coordination complexes. In addition to the possibility of the construction of a quantitative energy level diagram as the one showed in Fig. 9, the comparison of very similar results arising from completely different techniques, as UV-visible and XANES spectroscopies, guarantees and reinforces the assignment of the transitions. Moreover, the inclusion of resonance Raman results represents also an indirect corroboration of the assignment of one of the electronic transition.

\section{Acknowledgements}

C.O.D.V. and R.M.R. thank Ministerio de Ciencias, Tecnología e Innovación Productiva (MinCyT) (Programa de cooperación MinCyT SOLEIL 2011, proposal 20110916), Consejo Nacional de Investigaciones Científicas y Técnicas (CONICET) (PIP-0352), Agencia Nacional 
Científica y Tecnológica (ANPCyT) (PICT11-0647 and PICT14-3266) and Facultad de Ciencias Exactas, Universidad Nacional de La Plata (UNLP11/X684), República Argentina, for financial support. This work has been largely supported by Soleil, under proposal 20110916, and the Brazilian Synchrotron Light Source (LNLS), under proposals SXS-16287 and XAFS1-17950. The authors wish to thank the ANTARES (Soleil), SXS and XAFS1 (LNLS) beam line staffs for their assistance throughout the experiments.

\section{Appendix A. Supplementary data}

Absorption maximum and molar absorptivities $(\varepsilon)$ for each peak, obtained by UV-visible spectroscopy in solvents with different polarities (Table S1), comparison between experimental and theoretical vibrational bands, IR and Raman experimental and calculated (B3LYP/6$31+\mathrm{G}^{*}$ ) wavenumbers $\left(\mathrm{cm}^{-1}\right)$ (Table S2), FT-IR and Raman (between 3250 and $100 \mathrm{~cm}^{-1}$ ) spectra of $\mathrm{Ni}\left(\mathrm{CH}_{3}\left(\mathrm{CH}_{2}\right)_{2} \mathrm{OC}(\mathrm{S}) \mathrm{S}\right)_{2}$ (Fig. S1). Supplementary data associated with this article can be found in the online version, at http://dx.doi.org/10.1016/j.saa.2017.03.002.

\section{References}

[1] C. Garino, E. Borfecchia, R. Gobetto, J.A. van Bokhoven, C. Lamberti, Determination of the electronic and structural configuration of coordination compounds by synchrotron-radiation techniques, Coord. Chem. Rev. 277 (2014) 130-186, http://dx.doi. org/10.1016/j.ccr.2014.03.027.

[2] (a) J. Stöhr, NEXAFS Spectroscopy, Springer Series in Surface Sciences, 1996;

(b) J.G. Chen, NEXAFS investigations of transition metal oxides, nitrides, carbides, sulfides and other interstitial compounds, Surf. Sci. Rep. 30 (1997) 1-152, http://dx.doi.org/10.1016/S0167-5729(97)00011-3;

(c) D.C. Koningsberger, R. Prins, X-ray Absorption: Principles, Applications, Techniques of EXAFS SEXAFS, and XANES, Vol. 91, John Wiley \& Sons, 1988;

(d) A.V. Soldatov, X-ray absorption near edge structure as a source of structural information, J. Struct. Chem. 49 (Supplement 1) (2008) 102-106.

[3] A. Vairavamurthy, Using X-ray absorption to probe sulfur oxidation states in complex molecules, Spectrochim. Acta A Mol. Biomol. Spectrosc. 54 (1998) 2009-2017, http://dx.doi.org/10.1016/S1386-1425(98)00153-X.

[4] B. Flemmig, H. Modrow, K. Heinz Hallmeier, J. Hormes, J. Reinhold, R. Szargan, Sulfur in different chemical surroundings - S K XANES spectra of sulfur-containing heterocycles and their quantum-chemically supported interpretation, Chem. Phys. 270 (2001) 405-413, http://dx.doi.org/10.1016/S0301-0104(01)00415-3.

[5] A. Dey, S.P. Jeffrey, M. Darensbourg, K.O. Hodgson, B. Hedman, E.I. Solomon, Sulfur K-edge XAS and DFT studies on Nill complexes with oxidized thiolate ligands: implications for the roles of oxidized thiolates in the active sites of Fe and Co nitrile hydratase, Inorg. Chem. 46 (2007) 4989-4996, http://dx.doi.org/10.1021/ic0702441.

[6] L.C. Juncal, Y.A. Tobón, O.E. Piro, C.O. Della Védova, R.M. Romano, Structural, spectroscopic and theoretical studies on dixanthogens: $(\operatorname{ROC}(\mathrm{S}) \mathrm{S})_{2}$, with $\mathrm{R}=\mathrm{n}$-propyl and isopropyl, New J. Chem. 38 (2014) 3708, http://dx.doi.org/10.1039/C4NJ00708E.

[7] L.C. Juncal, M.V. Cozzarín, R.M. Romano, Conformational and spectroscopic study of xanthogen ethyl formates, $\mathrm{ROC}(\mathrm{S}) \mathrm{SC}(\mathrm{O}) \mathrm{OCH}_{2} \mathrm{CH}_{3}$. Isolation of $\mathrm{CH}_{3} \mathrm{CH}_{2} \mathrm{OC}(\mathrm{O}) \mathrm{SH}$, Spectrochim. Acta A Mol. Biomol. Spectrosc. 139 (2015) 346-355, http://dx.doi. org/10.1016/j.saa.2014.12.086.

[8] N. Alam, M.S. Hill, G. Kociok-Köhn, M. Zeller, M. Mazhar, K.C. Molloy, Pyridine adducts of nickel(II) xanthates as single-source precursors for the aerosol-assisted chemical vapor deposition of nickel sulfide, Chem. Mater. 20 (2008) 6157-6162, http://dx.doi.org/10.1021/cm801330v.

[9] P.L. Musetha, N. Revaprasadu, M. Malik, P. O'Brien, The use of xanthates as precursors for the deposition of nickel sulfide thin films by aerosol assisted chemical vapour deposition, MRS Proc. 879 (2005) Z7.4, http://dx.doi.org/10.1557/PROC-879-Z7.4.

[10] P.K. Ackerman, G.H. Harris, R.R. Klimpel, F.F. Aplan, Use of xanthogen formates as collectors in the flotation of copper sulfides and pyrite, Int. J. Miner. Process. 58 (2000) 1-13, http://dx.doi.org/10.1016/S0301-7516(99)00068-X.

[11] E.M. Donaldson, Solvent extraction of metal xanthates, Talanta 23 (1976) 417-426, http://dx.doi.org/10.1016/0039-9140(76)80121-X.

[12] E.C. Larsen, J.F. Hatcher, R.M. Adibhatla, Effect of tricyclodecan-9-yl potassium xanthate (D609) on phospholipid metabolism and cell death during oxygen-glucose deprivation in PC12 cells, Neuroscience 146 (2007) 946-961, http://dx.doi.org/10. 1016/j.neuroscience.2007.02.022.

[13] M.W. Whitehouse, P.D. Cookson, G. Siasios, E.R. Tiekink, Anti-arthritic activity in rats of some phosphinegold(I) thionucleobases and related thiolates, Metal-Based Drugs 5 (1998) 245-249, http://dx.doi.org/10.1155/MBD.1998.245.

[14] D. de Vos, S.Y. Ho, E.R.T. Tiekink, Cytotoxicity profiles for a series of triorganophosphinegold(I) dithiocarbamates and triorganophosphinegold(I) xanthates, Bioinorg. Chem. Appl. 2 (2004) 141-154, http://dx.doi.org/10.1155/ S156536330400010X

[15] W. Friebolin, G. Schilling, M. Zöller, E. Amtmann, Synthesis and structure - activity relationship of novel antitumoral platinum xanthate complexes, J. Med. Chem. 47 (2004) 2256-2263, http://dx.doi.org/10.1021/jm0309405.
[16] W. Friebolin, G. Schilling, M. Zöller, E. Amtmann, Antitumoral activity of non-platinum xanthate complexes, J. Med. Chem. 48 (2005) 7925-7931, http://dx.doi.org/ 10.1021/jm040899l.

[17] V. Gandin, A.P. Fernandes, M.P. Rigobello, B. Dani, F. Sorrentino, F. Tisato, M. Björnstedt, A. Bindoli, A. Sturaro, R. Rella, C. Marzano, Cancer cell death induced by phosphine gold(I) compounds targeting thioredoxin reductase, Biochem. Pharmacol. 79 (2010) 90-101, http://dx.doi.org/10.1016/j.bcp. 2009.07.023.

[18] M.J. Cox, E.R.T. Tiekink, Crystal and molecular structures of bis(O-npropyldithiocarbonato)-nickel(II) and bis(O-i-propyldithiocarbonato)nickel(II), Zeitschrift Für Krist. - Cryst. Mater. 211 (1996), http://dx.doi.org/10.1524/zkri. 1996.211.2.111.

[19] L.C. Juncal, Preparación, caracterización y estudio de las propiedades de compuestos xantatos y xantógenos con potenciales aplicaciones farmacológicas, PhD Thesis, Universidad Nacional de La Plata, 2014.

[20] C.C. Dewitt, E.E. Roper, The surface relations of potassium ethyl xanthate and pine oil. I, J. Am. Chem. Soc. 54 (2) (1932) 444-455

[21] G.W. Watt, B.J. McCormick, The synthesis and characterization of methyl and ethylxanthato complexes of $\mathrm{Pt}(\mathrm{II}), \mathrm{Pd}(\mathrm{II}), \mathrm{Ni}(\mathrm{II}), \mathrm{Cr}(\mathrm{III})$ and $\mathrm{Co}(\mathrm{III})$, J. Inorg. Nucl. Chem. 27 (1965) 898-900, http://dx.doi.org/10.1016/00221902(65)80453-5.

[22] N.J. Turro, V. Romamurthy, J.C. Scaiano, Principles of Molecular Photochemistry: An Introduction, University Science Books, Sausalito, CA, 2009.

[23] P. Klán, J. Wirz, Photochemistry of Organic Compounds, John Wiley \& Sons, From concepts to practice, 2009.

[24] H. Kuhn, H. Forsterling, D.H. Waldeck, Principles of Physical Chemistry, second ed. John Wiley \& Sons, Inc. Hoboken, New Jersey, 2009.

[25] T.A. Keyeta, A.V. Gholap, Determination of oscillator strength of caffeine and caffeine in tea leaves by the integrated absorption coefficient technique at two different temperatures, J. Eng. Technol. Res. 3 (2011) 155-160.

[26] J. Avila, I. Razado-Colambo, S. Lorcy, B. Lagarde, J.L. Giorgetta, F. Polack, M.C. Asensio, ANTARES, a scanning photoemission microscopy beamline at SOLEIL, J. Phys. Conf. Ser. 425 (2013) 192023.

[27] J. Avila, M.C. Asensio, First nanoARPES user facility available at Soleil: an innovative and powerful tool for studying advanced materials, Synchrotron Radiat. News 27 (2) (2014) 24-30.

[28] H. Tolentino, V. Compagnon-Cailhol, F.C. Vicentin, M. Abbate, The LNLS soft X-ray spectroscopy beamline, J. Synchrotron Radiat. 5 (1998) 539-541.

[29] M. Abbate, F.C. Vicentin, V. Compagnon-Cailhol, M.C. Rocha, H. Tolentino, The soft Xray spectroscopy beamline at the LNLS: technical description and commissioning results, J. Synchrotron Radiat. 6 (1999) 964-972.

[30] H.C.N. Tolentino, A.Y. Ramos, M.C.M. Alves, R.A. Barrea, E. Tamura, J.C. Cezar, N. Watanabe, A 2.3 to $25 \mathrm{keV}$ XAS beamline at LNLS, J. Synchrotron Rad. 8 (2001) 1040-1046.

[31] H. Tolentino, J.C. Cezar, D.Z. Cruz, V. Compagnon-Cailhol, E. Tamura, M.C. Martins Alves, Commissioning and first results of the LNLS XAFS beamline, J. Synchrotron Radiat. 5 (1998) 521-523.

[32] M.G. Helander, M.T. Greiner, Z.B. Wang, Z.H. Lu, Pitfalls in measuring work function using photoelectron spectroscopy, Appl. Surf. Sci. 256 (2010) 2602-2605, http://dx. doi.org/10.1016/j.apsusc.2009.11.002.

[33] S. Gutmann, M. Conrad, M.A. Wolak, M.M. Beerbom, R. Schlaf, Work function measurements on nano-crystalline zinc oxide surfaces, J. Appl. Phys. 111 (2012) 123710, http://dx.doi.org/10.1063/1.4729527.

[34] B. Ravel, M. Newville, ATHENA, ARTEMIS, HEPHAESTUS: data analysis for X-ray absorption spectroscopy using IFEFFIT, J. Synchrotron Radiat. 12 (2005) 537-541, http://dx.doi.org/10.1107/S0909049505012719.

[35] Y. Joly, X-ray absorption near-edge structure calculations beyond the muffin-tin approximation, Phys. Rev. B 63 (2001) 125120, http://dx.doi.org/10.1103/PhysRevB. 63.125120.

[36] E.I. Solomon, B. Hedman, K.O. Hodgson, A. Dey, R.K. Szilagyi, Ligand K-edge Xray absorption spectroscopy: covalency of ligand-metal bonds, Coord. Chem. Rev. 249 (2005) 97-129, http://dx.doi.org/10.1016/j.ccr.2004.03.020.

[37] M.J. Frisch, G.W. Trucks, H.B. Schlegel, G.E. Scuseria, M.A. Robb, J.R. Cheeseman, J.A. Montgomery Jr., T. Vreven, K.N. Kudin, J.C. Burant, J.M. Millam, S.S. Iyengar, J. Tomasi, V. Barone, B. Mennucci, M. Cossi, G. Scalmani, N. Rega, G.A. Petersson, H. Nakatsuji, M. Hada, M. Ehara, K. Toyota, R. Fukuda, J. Hasegawa, M. Ishida, T. Nakajima, Y. Honda, O. Kitao, H. Nakai, M. Klene, X. Li, J.E. Knox, H.P. Hratchian, J.B. Cross, C. Adamo, J. Jaramillo, R. Gomperts, R.E. Stratmann, O. Yazyev, A.J. Austin, R. Cammi, C. Pomelli, J.W. Ochterski, P.Y. Ayala, K. Morokuma, G.A. Voth, P. Salvador, J.J. Dannenberg, V.G. Zakrzewski, S. Dapprich, A.D. Daniels, M.C. Strain, O. Farkas, D.K. Malick, A.D. Rabuck, KJ. Raghavachari, B. Foresman, JV. Ortiz, Q Cui, A.G. Baboul, S. Clifford, J. Cioslowski, B.B. Stefanov, G. Liu, A. Liashenko, P. Piskorz, I. Komaromi, R.L. Martin, D.J. Fox, T. Keith, M.A. ALaham, C.Y. Peng, A. Nanayakkara, M. Challacombe, P.M.W. Gill, B. Johnson, W. Chen, M.W. Wong, C. Gonzalez, J.A. Pople, Gaussian 03, Revision B.01, Gaussian, Inc., Pittsburgh PA, 2003.

[38] S. Wei, P. Gao, Y. Zhao, H. Wang, X. Zheng, Photofragmentation mechanisms of nickel methyl xanthate-resonance Raman and density functional theory investigation, J. Raman Spectrosc. 42 (2011) 1025-1033, http://dx.doi.org/10. $1002 /$ jrs.2814

[39] R. Bauernschmitt, R. Ahlrichs, Treatment of electronic excitations within the adiabatic approximation of time dependent density functional theory, Chem. Phys. Lett. 256 (1996) 454-464, http://dx.doi.org/10.1016/0009-2614(96)00440-X.

[40] R.E. Stratmann, G.E. Scuseria, M.J. Frisch, An efficient implementation of time-dependent density-functional theory for the calculation of excitation energies of large molecules, J. Chem. Phys. 109 (1998) 8218-8224, http://dx.doi.org/10.1063/ 1.477483 . 
[41] N.M. O'boyle, A.L. Tenderholt, K.M. Langner, cclib: a library for package-independent computational chemistry algorithms, J. Comput. Chem. 29 (2008) 839-845, http:// dx.doi.org/10.1002/jcc.20823.

[42] R. Dennington II, T. Keith, J. Millam, GaussView, Version 4.1, Semichem, Inc., Shawnee Mission, KS, 2007.

[43] R. Dingle, Electronic spectrum of crystalline bis(diethyldithiocarbamato)nickel(II), Inorg. Chem. 10 (1971) 1141-1144, http://dx.doi.org/10.1021/ic50100a007.

[44] A.R. Latham, V.C. Hascall, H.B. Gray, The electronic structures and spectral properties of the square-planar dithiooxalate complexes of nickel(II), palladium (II), platinum (II), and gold (III), Inorg. Chem. 4 (1965) 788-792, http://dx.doi.org/10.1021/ ic50028a004.

[45] F. Drawert, K.-H. Reuther, F. Born, Über Xanthogenate von Alkoholen, Chem. Ber. 93 (1960) 3056-3065, http://dx.doi.org/10.1002/cber.19600931237.

[46] H.Y. Isci, O. Dag, W.R. Mason, Electronic-structure and spectra for square complexes containing sulfur-donor ligands - $\mathrm{M}(\text { Dto })_{2}(2+)(\mathrm{M}=\mathrm{Pt}(\mathrm{II}), \mathrm{Pd}(\mathrm{II})-\mathrm{Dto}=3,6$ Dithiaoctane), $\mathrm{M}(\mathrm{Scn})_{4}(2-) \mathrm{M}=\mathrm{Pt}(\mathrm{II}), \mathrm{Pd}(\mathrm{II})$, and $\mathrm{M}(\mathrm{Et}-\mathrm{Xan})(2)(\mathrm{M}=\mathrm{Pt}(\mathrm{II}), \mathrm{Pd}(\mathrm{II})$, $\mathrm{Ni}(\mathrm{II})$ - Et-Xan- $=\mathrm{C}_{2} \mathrm{H}_{5} \mathrm{OCS}-\mathrm{2}$ ), Inorg. Chem. 32 (1993) 3909-3914, http://dx.doi. org/10.1021/Ic00070a022.

[47] G.V. Romanenko, N.V. Podberezskaya, I.A. Baidina, V.V. Bakakin, S.V. Borisov, The crystal structure of bis(trifluoroethylxanthato)palladium(II) $\mathrm{Pd}\left(\mathrm{S}_{2} \mathrm{COCH}_{2} \mathrm{CF}_{3}\right)_{2}$ and various crystal-chemical characteristics of alkylxanthates, J. Struct. Chem. 20 (1979) 439-445, http://dx.doi.org/10.1007/BF00746820.

[48] G.W. Watt, B.J. McCormick, The infrared spectra and structure of transition metal xanthates, Spectrochim. Acta 21 (1965) 753-761, http://dx.doi.org/10.1016/03711951(65)80032-7.

[49] A. Ray, D.N. Sathyanarayana, G.D. Prasad, C.C. Patel, Infrared spectral assignments of methyl and ethyl xanthato complexes of nickel(II), Spectrochim. Acta A: Mol. Spectrosc. 29 (1973) 1579-1584, http://dx.doi.org/10.1016/05848539(73)80108-4

[50] K.J. Cavell, C.G. Sceney, J.O. Hill, R.J. Magee, Thermal studies on nickel alkyl xanthate complexes, Thermochim. Acta 5 (1973) 319-328, http://dx.doi.org/10.1016/00406031(73)85010-5.

[51] R.M. Romano, C.O. Della Védova, N-Sulfinylimine compounds, $\mathrm{R}-\mathrm{N}=\mathrm{S}=\mathrm{O}$ : a chemistry family with strong temperament, J. Mol. Struct. 522 (2000) 1-26, http://dx.doi. org/10.1016/S0022-2860(99)00453-6.

[52] R.A. Walton, The x-ray photoelectron spectra of metal complexes of sulfur-containing ligands: sulfur 2p binding energies, Coord. Chem. Rev. 31 (1980) 183-220, http://dx.doi.org/10.1016/S0010-8545(00)80449-X.

[53] J. Szépvölgyi, A. Tüdös, I. Bertóti, X-ray photoelectron spectroscopy studies on solid xanthates, J. Electron Spectrosc. Relat. Phenom. 50 (1990) 239-250, http://dx.doi. org/10.1016/0368-2048(90)87068-Y.

[54] L.N. Mazalov, S.V. Trubina, I.M. Oglezneva, N.A. Kryuchkova, O.V. Tarasenko, V.L. Varand, T.E. Kokina, S.V. Larionov, X-ray photoelectron and voltammetry studies of the charged state of the metal atom in nickel(II) chelate complexes with ligands containing $\mathrm{CS}_{2}{ }^{-}$and $\mathrm{PS}_{2}{ }^{-}$groups and in their mixed-ligand complexes, J. Struct. Chem. 46 (2005) 542-545, http://dx.doi.org/10.1007/s10947-006-0136-8.

[55] A. Thompson, D. Attwood, E.M. Gullikson, M. Howells, K.J. Kim, J. Kirz, J. Kortright, I. Lindau, L. Yanwei, P. Pianetta, A. Robinson, J. Scofield, J. Underwood, G. Williams, H. Winick, L.F. Robinson, X-ray data booklet, Berkeley Natl. Lab. 8 (2001) 1125, http:// dx.doi.org/10.1107/S090904950100807X.

[56] A. Dey, M. Chow, K. Taniguchi, P. Lugo-Mas, S. Davin, M. Maeda, J.A. Kovacs, M. Odaka, K.O. Hodgson, B. Hedman, E.I. Solomon, Sulfur K-edge XAS and DFT calculations on nitrile hydratase: geometric and electronic structure of the nonheme iron active site, J. Am. Chem. Soc. 128 (2006) 533-541, http://dx.doi.org/10 1021/ja0549695.

[57] S.E. Shadle, B. Hedman, K.O. Hodgson, E.I. Solomon, Ligand K-edge X-ray absorption spectroscopic studies: metal-ligand covalency in a series of transition metal tetrachlorides, J. Am. Chem. Soc. 117 (1995) 2259-2272, http://dx.doi.org/10.1021/ ja00113a015.

[58] K. Rose Williams, B. Hedman, K.O. Hodgson, E.I. Solomon, Ligand K-edge X-ray absorption spectroscopic studies: metal-ligand covalency in transition metal tetrathiolates, Inorg. Chim. Acta 263 (1997) 315-321, http://dx.doi.org/10.1016/ S0020-1693(97)05663-6.

[59] S.E. Shadle, B. Hedman, K.O. Hodgson, E.I. Solomon, Ligand K-edge X-ray absorption spectroscopy as a probe of ligand-metal bonding: charge donation and covalency in copper-chloride systems, Inorg. Chem. 33 (1994) 4235-4244, http://dx.doi.org/10. 1021/ic00097a009.

[60] M.S. Queen, B.D. Towey, K.A. Murray, B.S. Veldkamp, H.J. Byker, R.K. Szilagyi, Electronic structure of $\left[\mathrm{Ni}(\mathrm{II}) \mathrm{S}_{4}\right]$ complexes from S K-edge X-ray absorption spectroscopy, Coord. Chem. Rev. 257 (2013) 564-578, http://dx.doi.org/10.1016/j.ccr.2012.07. 020.

[61] R. Sarangi, S.D. George, D.J. Rudd, R.K. Szilagyi, X. Ribas, C. Rovira, M. Almeida, K.O Hodgson, B. Hedman, E.I. Solomon, Sulfur K-edge X-ray absorption spectroscopy as a probe of ligand-metal bond covalency: metal vs ligand oxidation in copper and nickel dithiolene complexes, J. Am. Chem. Soc. 129 (2007) 2316-2326, http:// dx.doi.org/10.1021/ja0665949.

62] R. Sarangi, P. Frank, K.O. Hodgson, B. Hedman, When identical functional groups are not identical: a DFT study of the effects of molecular environment on sulfur K-edge X-ray absorption spectra, Inorg. Chim. Acta 361 (2008) 956-964, http://dx.doi.org/ 10.1016/j.ica.2007.05.047.

[63] S. Sproules, K. Wieghardt, Dithiolene radicals: sulfur K-edge X-ray absorption spectroscopy and Harry's intuition, Coord. Chem. Rev. 255 (2011) 837-860, http://dx. doi.org/10.1016/j.ccr.2010.12.006.

[64] I.J. Pickering, G.N. George, J.T. Lewandowski, A.J. Jacobson, Nickel K-edge x-ray absorption fine structure of lithium nickel oxides, J. Am. Chem. Soc. 115 (1993) 4137-4144, http://dx.doi.org/10.1021/ja00063a035.

[65] N.N. Trofimova, Y.V. Zubavichus, O.I. Titova, E.A. Karpyuk, V.A. Ivanov, A.D Pomogailo, Y.L. Slovokhotov, Local coordination of $\mathrm{Co}^{2+}$ and $\mathrm{Ni}^{2+}$ cations in polyacrylate matrices, Bull. Russ. Acad. Sci. Phys. 77 (2013) 1127-1130, http://dx doi.org/10.3103/S1062873813090463.

[66] G. van der Laan, J. Zaanen, G.A. Sawatzky, R. Karnatak, J.-M. Esteva, Comparison of Xray absorption with X-ray photoemission of nickel dihalides and NiO, Phys. Rev. B 33 (1986) 4253-4263, http://dx.doi.org/10.1103/PhysRevB.33.4253.

[67] Y. Ufuktepe, G. Akgül, F. Aksoy, D. Nordlund, Thickness and angular dependence of the L-edge X-ray absorption of nickel thin films, X-Ray Spectrom. 40 (2011) 427-431, http://dx.doi.org/10.1002/xrs.1362.

[68] M. Medarde, A. Fontaine, J.L. García-Muñoz, J. Rodríguez-Carvajal, M. de Santis, M. Sacchi, G. Rossi, P. Lacorre, $\mathrm{RNiO}$ perovskites $(\mathrm{R}=\mathrm{Pr}, \mathrm{Nd})$ : nickel valence and the metal-insulator transition investigated by x-ray-absorption spectroscopy, Phys. Rev. B 46 (1992) 14975-14984, http://dx.doi.org/10.1103/PhysRevB.46.14975.

[69] L.N. Mazalov, N.A. Kryuchkova, G.K. Parygina, O.A. Tarasenko, S.V. Trubina, Electronic structure and X-ray spectra of nickel(II) dithiolate chelate complexes, J. Struct. Chem. 49 (2008) 19-39, http://dx.doi.org/10.1007/s10947-008-0198-x. 